Article

\title{
The Influence of Formulation Ratio and Emulsifying Settings on Tri-Fuel (Diesel-Ethanol-Biodiesel) Emulsion Properties
}

\author{
M. Mukhtar N. A. ${ }^{1}$, Abd Rashid Abd Aziz ${ }^{2}$, Ftwi Y. Hagos ${ }^{1,3, *(\mathbb{D}, \text { M. M. Noor }}{ }^{3,4}(\mathbb{D}$, \\ Kumaran Kadirgama ${ }^{3,4}$, Rizalman Mamat ${ }^{1,3}$ and A. Adam Abdullah 1,3 \\ 1 Advance Fluids Focus Group, Faculty of Mechanical Engineering, Universiti Malaysia Pahang, \\ Pekan 26600, Pahang, Malaysia; pmm16009@stdmail.ump.edu.my (M.M.N.A.); \\ rizalman@ump.edu.my (R.M.); adam@ump.edu.my (A.A.A.) \\ 2 Center for Automotive Research Electric Mobility (CAREM), Universiti Teknologi Petronas, \\ Tronoh 31750, Perak, Malaysia; rashid@utp.edu.my \\ 3 Automotive Engineering Centre, Universiti Malaysia Pahang, Universiti Malaysia Pahang, \\ Pekan 26600, Pahang, Malaysia; muhamad@ump.edu.my (M.M.N.); kumaran@ump.edu.my (K.K.) \\ 4 Automotive Engineering Research Group, Faculty of Mechanical Engineering, Universiti Malaysia Pahang, \\ Pekan 26600, Pahang, Malaysia \\ * Correspondence: ftwi@ump.edu.my
}

Received: 31 January 2019; Accepted: 8 March 2019; Published: 6 May 2019

check for updates

\begin{abstract}
In this study, an alternative fuel for compression ignition (CI) engines called tri-fuel emulsion was prepared using an ultrasonic emulsifier. The objective of the study is to investigate the effect of emulsifying settings and formulation ratio on the physicochemical properties of tri-fuel emulsions. Design of experiment (DOE) with the two-level factorial design was employed to analyze the effect of emulsifying settings such as time, amplitude, and cycle along with the variation ratio of tri-fuel emulsion components as control factors. Numbers of responses identified were important parameters that may contribute to microexplosion phenomenon in $\mathrm{CI}$ engine. Analysis of variance (ANOVA) was carried out for each response, and the results indicated that density, dynamic viscosity, surface tension, and average droplet size were influenced by specific preparation control factors. Furthermore, interaction among the control factors was found to affect the responses as well. Interaction means the effect of two factors together is different than what would be expected from each factor separately. Besides, the stability of the tri-fuel emulsion was observed for three months. Furthermore, a qualitative approach with a multiobjective lens digital microscope revealed the geometry of freshly made dispersed tri-fuel emulsion droplets. Microscopic examination on tri-fuel emulsion droplets has shown that the dispersed ethanol capsulated within diesel with the help of biodiesel is similar to a water in diesel emulsion and is dissimilar to commercial diesel mixed with fatty acid methyl esters found in the market.
\end{abstract}

Keywords: emulsion; diesel; biodiesel; ethanol; tri-fuel; emulsifying setting

\section{Introduction}

Compression ignition, the core principle of a diesel engine, permits high compression ratio which has been used for decades. The engine has a significant share in transportation and various industries. It was reported in 2014 in some European countries that the diesel vehicle market share has exceeded $60 \%$. Nonetheless, the world diesel engine sales were forecasted to rise by $7.7 \%$ annually through 2017 [1], while the fact was not as expected. Despite predictions, between 2010 to 2040, gasoline demand decreased by $10 \%$, while diesel had higher demand up to $85 \%$ [2]. Though diesel engines 
have preferable advantages compared to other engines, according to BP's Statistical Review 2017, diesel fuel demand is decreasing for the first time since 2009 due to industrial slowdown. While part of this is due to concern about fuel demand and supply, it is also related to ecological concern and human health, which damaged by diesel engine emissions [3-6]. The main disadvantage of this engine category is the emission of unwanted particles in the long run [7]. Hence, replacement fuel may be desirable to overcome the problems of such emission and sustain the CI engine with the hope for better performance. In other words, to maintain the compression ignition (CI) engine, it is necessary to discover alternative fuel. With recent development of second-generation bioethanol $[8,9]$ and second-generation biodiesel production [10,11], mixing diesel with biofuels could be a promising option, and it should be able to be introduced without significant modification of the engine.

Biofuels have been introduced to the $\mathrm{CI}$ engine as stand-alone [12] and diesel-accompanied, known as blended fuel $[6,13]$. Ethanol was introduced due to its high volatility that potentially contributes to secondary atomization, known as the microexplosion phenomenon [14-25]. Meanwhile, ethanol belongs to the alcohol family and is polar, similar to water. Since ethanol and diesel are known to be immiscible in nature, palm methyl-ester or biodiesel have been identified as co-solvents and natural surfactants [26-30]. The remaining task is to resolve the immiscibility issue of alcohol and diesel. By definition, an emulsion is a mixture of two or more liquids which are immiscible by nature with the aid of surfactant [31]. It was reported that tri-fuel is essential in emission reduction [6]. Unfortunately, it is nearly impossible to form an emulsion via normal agitation such as stirring or shaking. Even with the presence of an emulsification agent, the mixture will be separated within seconds of the machine being switch off. An ultrasonic emulsifier, however, has been identified as one of the effective mixing instruments [32,33], with the capability of producing a stable emulsion with a lower amount of surfactant required in comparison to conventional methods of blending or mixing [34-37]. Nevertheless, information regarding the formulation ratio combined with emulsifying setting, such as amplitude, cycle, and period, are limited in the literature which utilized emulsified tri-fuel.

The aim of this study is to identify the effect of emulsification setting and formulation ratio on physicochemical properties of tri-fuel emulsions for a CI engine. Physicochemical properties selected are relevant to the studies of spray and droplet atomization.

\section{Material and Methods}

\subsection{Materials}

For the formulation of the tri-fuel emulsion, the materials required are diesel, palm methyl ester, and ethanol. Distillate diesel fuel without additive was obtained from an available supplier in Kuantan, Pahang, Malaysia, meeting the specifications of Malaysia standards (SIRIM) and Euro 2M standards. Detailed specification is presented in Table 1. Similarly, biodiesel from palm oil origin or a synonymous name, Palm Oil Methyl Esters, Biodiesel B100, and Fatty Acid Methyl Esters (FAME), was obtained from the local manufacturer along with anhydrous ethanol with purity of $99.9 \% v / v$. Detailed specification of biodiesel is presented in Table 2, while technical specification of ethanol is listed in Table 3. 
Table 1. Diesel's technical specifications.

\begin{tabular}{ccccc}
\hline Properties & Min & Max & Unit & Test Method \\
\hline Density D 4052-Density @ 15 ${ }^{\circ} \mathrm{C}$ & 0.81 & 0.87 & $\mathrm{Kg} / \mathrm{L} @$ 15 ${ }^{\circ} \mathrm{C}$ & ASTM D4052-15 \\
D86 Dist. Comp.-95\% Rec & & 370 & ${ }^{\circ} \mathrm{C}$ & ASTM D86-15 \\
Flashpoint comp-Flashpoint & 60 & & ${ }^{\circ} \mathrm{C}$ & ASTM D93-16 \\
K. viscosity Comp-viscosity 40 ${ }^{\circ} \mathrm{C}$ & 1.50 & 5.80 & $\mathrm{cSt}$ & ASTM D445-15A \\
Sulfur (X-ray)-Sulfur by X-ray & & 500 & $\mathrm{Mg} / \mathrm{kg}$ & ASTM D494-16A1 \\
Ash comp, ash & & 0.01 & $\mathrm{Wt} \%$ & ASTM D482-13 \\
MCRT Comp-Micro Carbon residue & & 0.20 & $\% \mathrm{owt}$ & ASTM D4530-15 \\
Water content-Water content & & 0.05 & $\%$ ovol & ASTM D95-13 \\
Sediment Comp-Sediment & & 0.01 & $\% w t$ & ASTM D473-12 \\
Color D1500 Comp-Colour D 1500 & \multirow{2}{*}{2.50} & None & ASTM D1500-07 \\
Cetane Index Comp-Cetane Ind & 49 & & None & ASTM D4737-10 \\
Cu. Corr.-Cu Corrosion & \multirow{2}{*}{50} & & 1a & ASTM D130-12 \\
Conductivity Comp-Cond diesel & & 19 & pS/M & ASTMD2624-15 \\
Auto Cloud Point-Cloud Point & & 460 & microns & ASTM D6079-11(201) \\
Lubricity & & & &
\end{tabular}

Table 2. Biodiesel's technical specifications.

\begin{tabular}{cc}
\hline Type Analysis & Data \\
\hline Appearance & Clear, Light Yellow liquid \\
Odor category & Soft \\
Physical form & Liquid \\
pH level & Neutral \\
Boiling point & $>200^{\circ} \mathrm{C}$ \\
Flash point & $>130{ }^{\circ} \mathrm{C}$ \\
Molecular weight & $170-200 \mathrm{~g} / \mathrm{mol}$ \\
Specific Gravity & $0.86-0.90 @ 15^{\circ} \mathrm{C}(\mathrm{H} 2 \mathrm{O}=1)$ \\
Water solubility & Minor solubility \\
Vapor pressure & 0.01 psi $100{ }^{\circ} \mathrm{F}, 38^{\circ} \mathrm{C}$ \\
Vapor density & Air $=1:>2$ \\
\hline
\end{tabular}

Table 3. Ethanol's technical specifications.

\begin{tabular}{cc}
\hline Type Analysis & Data \\
\hline Assay $\left(20{ }^{\circ} \mathrm{C}\right)$ & $99.90 \% v / v$ \\
Water Content & $0.195 \% w / w$ \\
Specific gravity $\left(20^{\circ} \mathrm{C} / 20{ }^{\circ} \mathrm{C}\right)$ & 0.791 \\
Clarity of solution & Clear \\
Apparent density $\left(20{ }^{\circ} \mathrm{C}\right)$ & $788.70 \mathrm{~kg} / \mathrm{m}^{3}$ \\
Aldehydes as acetaldehyde & $<50 \mathrm{ppm}$ \\
Nonvolatile matter & $1 \mathrm{ppm}$ \\
\hline
\end{tabular}

\subsection{Formulation Ratio and Emulsifying Setting}

The purpose of the experiment was to understand the effect of formulation ratio along with emulsifying setting on tri-fuel emulsion physicochemical properties relevant to the study of fuel injection, spray, and atomization. All the experiments were conducted at an ambient temperature between $24^{\circ} \mathrm{C}-26{ }^{\circ} \mathrm{C}$ and humidity recorded was between $50-60 \%$. Temperature increment of samples due to emulsification was recorded every minute and did not exceed $40{ }^{\circ} \mathrm{C}$. The level of ethanol concentration in each sample prepared was measured and verified with an alcohol hydrometer and a portable density/specific gravity meter (DA-130N) utilizing configuration mode of measuring alcohol concentration calculated from the density at the measurement temperature.

The emulsification time was selected based on the temperature level corresponding to the ethanol evaporation tendency and flash point. The emulsification settings, such as amplitude and cycle 
setting limit, were decided based on the temperature limit corresponding to ethanol's limit. Since the sensitivity of ethanol to the rise of temperature is one of the main hurdles when dealing with tri-fuel emulsion, the limit was set by considering the evaporation tendency with an open cap, time, and the specific rise of temperature. As an ultrasonic emulsifier may generate heat and could affect the fuel quantity in the mixture [34], apart from the temperature below the flashpoint level [38,39], the temperature range was decided within the acceptable evaporation rate. Figure $1 \mathrm{a}, \mathrm{b}$ represents the preliminary experimental results of ethanol evaporation response to the specific elevated temperature for a duration up to five minutes with an open-cap. The outcome was employed as the setting range benchmark for the cycle and amplitude setting for the primary experiment. The pattern indicated that the sensitivity of ethanol evaporation loss subject to the temperature change was aggressive after approximately $40^{\circ} \mathrm{C}$. Hence, preparation of the sample for the primary experiment was decided to be conducted below $40^{\circ} \mathrm{C}$ with constant temperature monitoring, and a duration of five minutes was selected as the analysis time for all samples with various amplitude and cycle setting, which satisfied the limitation. Table 4 displays the details of the emulsifier settings and formulation ratio.

Design of Experiment (DOE) is a flexible and quality-based approach [40] that utilizes a number of powerful statistical tools for quality control purposes $[29,41]$. In order to utilize this approach, commercial software was employed as a platform for the application of DOE with a two-level factorial design. The two-level factorial design is beneficial for estimation of main effects and interactions which may not be revealed by a traditional "one-factor-at-a-time" (OFAT) approach in order to achieve at least an $80 \%$ quality level. The remaining $20 \%$ quality could be achieved via response surface method (RSM), which has not been discussed in this study. The interaction between independent variables (factors) on specific dependent variables or responses was analyzed statistically. A total of 20 samples were prepared and randomly assigned to each of the physicochemical properties. The randomized order was for the reduction of lurking factors, such as time, temperature, and humidity. Four samples were the middle range setting for all factors and were replicated four times to provide sufficient information on possible curvature in the system. This is required in order to utilize RSM for any optimization approach in the future. The main effect of each control factor, known as its effect on the response, may not be similar at different levels of other control factors. In other words, the effect of one control factor may depend on the level of another control factor.

Four sets of crucial factors were selected in sample preparation. Factors from formulation ratio were the percentage of biodiesel and ethanol, in which diesel, as the base fluid, was the remaining percentage ratio formulation. To be specific, diesel was used as the base fuel which complements the variation setting of biodiesel and ethanol with a total combination of $100 \%$. Meanwhile, emulsification time, cycle, and amplitude were the emulsification control factors nominated for the experiment. All samples were prepared using Hielscher Ultrasonic Processor UP400S Emulsifier. It is known that a cycle is a pulse control mode which switches the ultrasonic processor on or off, while the difference of $1.0 \mathrm{~s}$ is the pause time. The experiment was carried out in two sections by varying the time. In the lower cycle, the power would be triggered for $0.1 \mathrm{~s}$ out of $1.0 \mathrm{~s}$ and would be paused for $0.9 \mathrm{~s}$. In the higher cycle, the power triggering time can be maintained for $0.9 \mathrm{~s}$ while being paused for $0.1 \mathrm{~s}$. The ultrasonic output is the rotary amplitude regulator type. Table 4 demonstrates the finalized emulsifier setting and formulation ratio, while Table 5 shows samples with the decided control factors. 


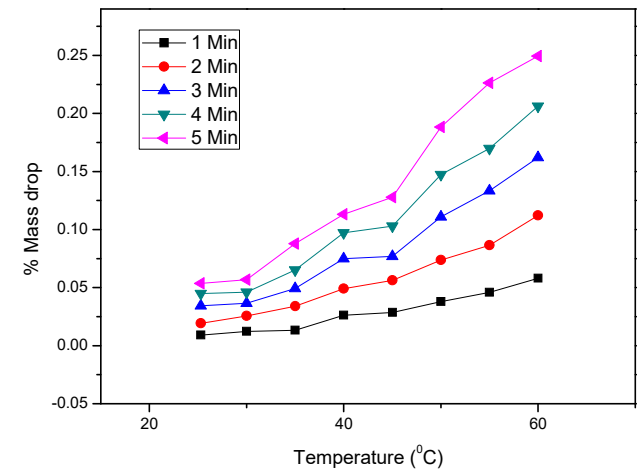

(a)

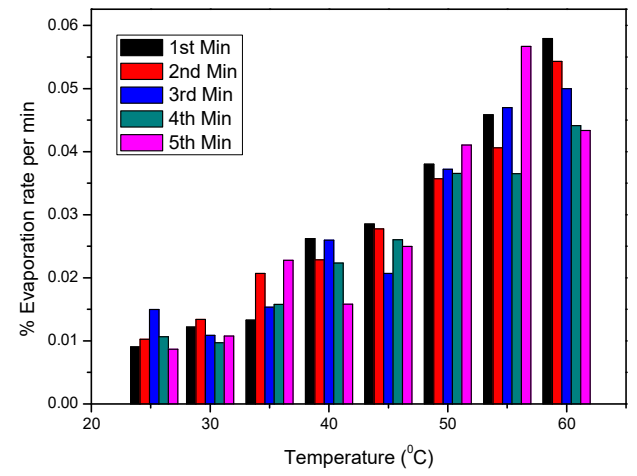

(b)

Figure 1. (a) Percentage mass drop of ethanol due to temperature increment within five minutes with open cap. (b) Percentage evaporation rate of ethanol each minute at different temperature with an open-cap.

Table 4. Finalized emulsifier setting and formulation ratio.

\begin{tabular}{cccc}
\hline Acronym & Formulation & Setting & Range \\
\hline- & Diesel & - & $70-90 \%$ \\
A & Ethanol & - & $5-15 \%$ \\
B & Biodiesel & - & $5-15 \%$ \\
C & - & Amplitude & $30-60 \%$ \\
D & - & Cycle & $0.4-0.6 / \mathrm{s}$ \\
- & - & Time & $5 \mathrm{~min}$ \\
\hline
\end{tabular}

Table 5. Samples with decided control factors.

\begin{tabular}{ccccccccccc}
\hline Sample & Std & Run & \multicolumn{2}{c}{ Ethanol (A) } & \multicolumn{2}{c}{ Biodiesel (B) } & \multicolumn{2}{c}{ Amplitude (C) } & \multicolumn{2}{c}{ Cycle (D) } \\
\hline 1 & 1 & 17 & 5 & -1 & 5 & -1 & 30 & -1 & 0.4 & -1 \\
2 & 2 & 7 & 15 & 1 & 5 & -1 & 30 & -1 & 0.4 & -1 \\
3 & 3 & 2 & 5 & -1 & 15 & 1 & 30 & -1 & 0.4 & -1 \\
4 & 4 & 19 & 15 & 1 & 15 & 1 & 30 & -1 & 0.4 & -1 \\
5 & 5 & 11 & 5 & -1 & 5 & -1 & 60 & 1 & 0.4 & -1 \\
6 & 6 & 20 & 15 & 1 & 5 & -1 & 60 & 1 & 0.4 & -1 \\
7 & 7 & 18 & 5 & -1 & 15 & 1 & 60 & 1 & 0.4 & -1 \\
8 & 8 & 8 & 15 & 1 & 15 & 1 & 60 & 1 & 0.4 & -1 \\
9 & 18 & 6 & 10 & 0 & 10 & 0 & 45 & 0 & 0.5 & 0 \\
10 & 20 & 12 & 10 & 0 & 10 & 0 & 45 & 0 & 0.5 & 0 \\
11 & 19 & 14 & 10 & 0 & 10 & 0 & 45 & 0 & 0.5 & 0 \\
12 & 17 & 16 & 10 & 0 & 10 & 0 & 45 & 0 & 0.5 & 0 \\
13 & 9 & 4 & 5 & -1 & 5 & -1 & 30 & -1 & 0.6 & 1 \\
14 & 10 & 15 & 15 & 1 & 5 & -1 & 30 & -1 & 0.6 & 1 \\
15 & 11 & 1 & 5 & -1 & 15 & 1 & 30 & -1 & 0.6 & 1 \\
16 & 12 & 3 & 15 & 1 & 15 & 1 & 30 & -1 & 0.6 & 1 \\
17 & 13 & 10 & 5 & -1 & 5 & -1 & 60 & 1 & 0.6 & 1 \\
18 & 14 & 13 & 15 & 1 & 5 & -1 & 60 & 1 & 0.6 & 1 \\
19 & 15 & 9 & 5 & -1 & 15 & 1 & 60 & 1 & 0.6 & 1 \\
20 & 16 & 5 & 15 & 1 & 15 & 1 & 60 & 1 & 0.6 & 1 \\
\hline
\end{tabular}

The analyzed responses with a two-level factorial approach were dynamic viscosity, density, surface tension, and average droplet size. As far as the selection process of the factorial design, no hard-to-change (HTC) factors were selected. Hence, the study did not consider the split point design. Twenty samples were prepared for each response and evaluated power was detected at more than 
$80 \%$, sufficient to reveal an active significant effect. Analysis of variance (ANOVA) was employed from the built-in tool in the commercial software.

\subsection{Density Test}

The density of all samples was measured at $20^{\circ} \mathrm{C} \pm 1{ }^{\circ} \mathrm{C}$ using a portable density/specific gravity meter (model DA-130N) with the supplied sampling nozzle vertical to the ground. The measuring method of the tool is the resonant frequency oscillation which was specified in ASTM D777, the standard test method of density by portable density meter. The measuring range capability of the density meter is from 0.0000 to $2.0000 \mathrm{~g} / \mathrm{cm}^{3}$ with resolution of $0.0001 \mathrm{~g} / \mathrm{cm}^{3}$ and accuracy of $\pm 0.001 \mathrm{~g} / \mathrm{cm}^{3}$. After the emulsification procedure, samples were cooled down to $20^{\circ} \mathrm{C}$ in a mini-refrigerator prior to measurements. In order to avoid evaporation of ethanol content in the tri-fuel emulsion, the prepared samples were stored in a tightly closed glass laboratory bottle with plastic screw cap. The procedure was repeated at least three times while the average value was obtained as the final reading to minimize the effect of systematic errors.

\subsection{Viscosity Test}

A Brookfield, DV-III Ultra Programmable Rheometer was utilized in order to measure the viscosity, and the software used was Brookfield Rheocalc V3.3 Build 49-1. Properties tested were in accordance with the petroleum standard ASTM D445 [42]. Dynamic viscosity in centipoise was measured by taking the ratio of shear stress multiply by 100 over the shear rate. Viscosity reading was obtained under laminar conditions (only directed by the shearing force), and average reading was obtained within the detected equivalent range of $10 \%$ to $100 \%$ torque reading for any combination of spindle speed rotation. The temperature of each sample was recorded at the initial stage of the spindle rotation, starting at $40^{\circ} \mathrm{C} \pm 1{ }^{\circ} \mathrm{C}$. The experiment was executed immediately after each sample preparation with at least three repetitions.

\subsection{Surface Tension Test}

In order to analyze the surface tension, a tension meter (Data Physics/DCAT 9T) was utilized. The method of surface tension measurement was validated via the Wilhelmy thin plate method, and the ring method test was used to countercheck result validity. Humidity and room temperature were controlled at $50 \%$ and $25{ }^{\circ} \mathrm{C} \pm 1{ }^{\circ} \mathrm{C}$, respectively. The experiment was executed immediately after each preparation of the sample with at least three repetitions. Properties tested were in accordance to the petroleum standard ASTM D971.

\subsection{Average Droplet Size Test}

Average droplet size can be obtained with Zetasizer machine [35,43]. Hence, the measuring procedure to obtain the average droplet size of 20 samples was executed via Zetasizer Nano S90 machine. A simple but highly sensitive machine manufactured by Malvern can determine the size by measuring the Brownian motion of the droplet in the sample. By definition, the Brownian motion is the random movement of a particle in the liquid as a result of surrounding bombardment motion of another particles [44]. Hence, by measuring the speed of the particle undergoing Brownian motion, the droplet size can be determined via dynamic light scattering (DLS) [45]. Since the DLS technique takes advantage of Brownian motion, the experiment cannot be conducted with unstable temperature or warm, freshly made tri-fuel emulsion due to the rapid Brownian motion produced by the warm temperature.

Nevertheless, within $24 \mathrm{~h}$ of preparation, all the samples were measured at a temperature at $25^{\circ} \mathrm{C} \pm 1{ }^{\circ} \mathrm{C}$. At such a stable temperature, the basic principle of DLS can be applied. In principle, slow Brownian motion indicates the existence of large particle, while rapid Brownian motion indicates smaller droplets. A glass covet was utilized as the standard container and cautiously poured with a micropipette. Size measurement dedicated by the machine should be ideally no more than 10 microns. 


\subsection{Stability Test}

The stability test method was conducted via a gravitational approach [46]. Five hundred $\mathrm{mL}$ volume per sample set was prepared, and a small portion of approximately $16 \mathrm{~mL}$ for each tube test was used for the stability test. Two sets of test tubes for each sample were examined to ensure repeatable results. A tube rack was utilized under room temperature between $24{ }^{\circ} \mathrm{C}$ and $36{ }^{\circ} \mathrm{C}$, while the humidity recorded was between $40 \%$ and $80 \%$, under closed-cap conditions. The samples were left under gravitational force in order to observe the phase separation daily. Twenty samples were prepared altogether and were cautiously poured into the test tube using a micropipette and properly sealed with aluminium foil. The observation was conducted for a total period of 100 days. Daily observation was performed for the first two weeks. The observation was then continued once per week until it reached the 4 th week. After that, the observation was taken monthly until the third month. The last reading was taken on the 100th day.

\subsection{Microstructure Test}

A digital microscope (Dolomite Celestron(CARIFF, Universiti Malaysia Pahang, Gambang, Malaysia) was employed with $5 \times, 10 \times$, and $40 \times$ objective lenses and total magnification up to $400 \times$. The sample was observed immediately after preparation within less than $1 \mathrm{~h}$ with $5 \times, 10 \times$, and $40 \times$ objective lenses.

\section{Results and Discussion}

\subsection{Density}

The final equation in terms of coded factors is shown as in Equation (1). This is the equation that relates ethanol as the input factor to the density as the output response.

$$
\rho=+0.81-0.006218 A
$$

where $\rho$ is density, and $A$ is ethanol.

The final Equation (2) in terms of actual factors:

$$
\rho=+0.82438-0.0012436 A
$$

It was found that ethanol $(A)$ has the highest influence on the density. Figure 2 illustrates the computing effect for model selection via half normal plot (a) and diagnostic plot (b) of residuals versus run with no random scatter and no outside limit detected. No statistical outliers were detected, indicating no model problems.

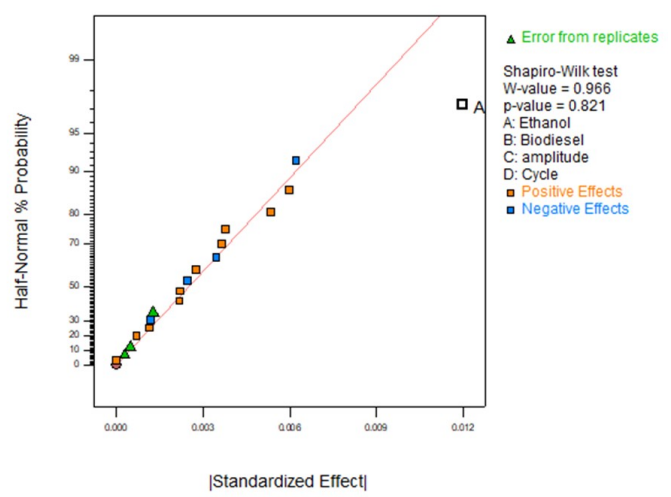

(a)

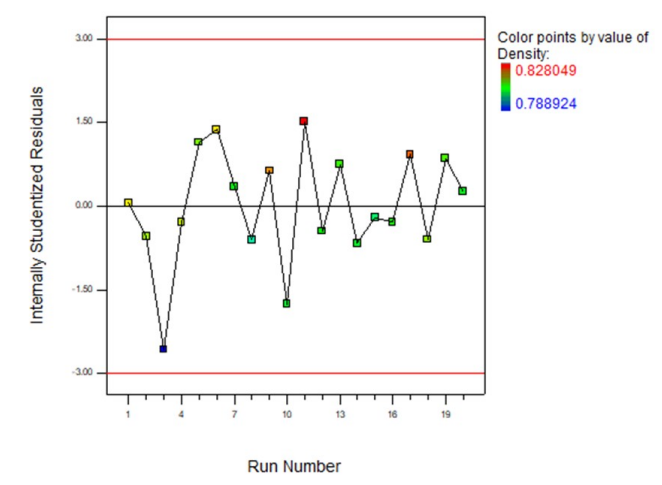

(b)

Figure 2. Density reading. Half-normal plot (a) and Residuals Analysis plot (b). 
It can be seen from the analysis of variance presented in Table 6 that the probability value of the model indicates that only ethanol's (A) influence on the density was statistically significant. In other words, it is unlikely that this happens by chance alone. The F-tests with $0.3774(>0.05)$ indicate no statistically significant value on the lack of a fit test, which is desirable. The curvature F value of 0.08 indicates that it is not necessary to proceed to higher quality analysis, such as the respond surface method (RSM) [47]. Figure 3 below presents the predicted versus experimental values for density.

Table 6. Analysis of variance (ANOVA) for the selected factorial model (Partial sum of the square-Type III) for response 1 (Density).

\begin{tabular}{|c|c|c|c|c|c|c|}
\hline \multirow{2}{*}{ Source } & Sum of & & Mean & F & $p$-Value & \multirow{2}{*}{ Remark } \\
\hline & Squares & 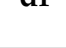 & Square & Value & Prob $>$ F & \\
\hline Model & 0.0006187 & 1 & 0.0006187 & 12.76 & 0.0023 & significant \\
\hline A-Ethanol & 0.0006187 & 1 & 0.0006187 & 12.76 & 0.0023 & \\
\hline Curvature & 0.000003681 & 1 & 0.000003681 & 0.076 & 0.7862 & not significant \\
\hline Residual & 0.0008243 & 17 & 0.00004849 & & & \\
\hline Lack of Fit & 0.0007298 & 14 & 0.00005213 & 1.65 & 0.3774 & not significant \\
\hline Pure Error & 0.00009458 & 3 & 0.00003153 & & & \\
\hline Cor Total & 0.001447 & 19 & & & & \\
\hline
\end{tabular}

Factor A was found to be not involved in any interaction with other factors. It was found that as the ethanol content increases, the values of density decreases. Furthermore, the effective detection was under the negative effect category. This indicates that by increasing the control factor of ethanol, the value of density decreases. In other words, higher content of ethanol yields a lower density reading.

Nevertheless, the decreasing level was considered to be likely due to biodiesel that compensates the dominancy of ethanol. The counterbalance of these opposite effects leads to the production of a tri-fuel emulsion which could compete with commercial diesel. In our previous work, the range of density in the mixing of diesel and biodiesel without incorporation of ethanol were above the density value of diesel [48]. However, in this study, incorporation of ethanol counterbalances the density to a very comfortable level, far from the maximum acceptable value of diesel standard ASTM D7467 and biodiesel maximum acceptable value ASTM D6751. The obtained data are in agreement with recent studies [38,39].

The rationale behind investigating the influence of all the factors on density is due to the fact that density is one of the main factors that affects the flow characteristic inside the injector nozzle, which consequently influences the momentum of the fuel injection spray [49]. If the density of the fuel is drastically decreased, the quality of the fuel may not be in favour of the existing engine setting. Peak injection rate may be expected to be deterred by the low-density effect. Consequently, it will delay the dynamic injection timing by at least 1-degree crank angle (CA). Besides, stoichiometric ratio is expected to be affected, since the reduction in density leads to lower fuel mass with the same volume, and the fuel-air mixture setting needs to be readjusted in order to achieve the desired burning efficiency.

In spark ignition (SI) engines, the stoichiometric ratio is normally around 14.7:1, while this ratio is around 16:1 and 12:1 for a lean mixture and rich mixture, respectively. However, the average stoichiometric air-fuel ratio on a mass basis is estimated to be 14.5:1 in a CI engine, while this value for rich and lean can be around 100:1 to 2:1. Control of the acceleration in a CI engine is performed by controlling the fuel, while in SI engines, this is executed by controlling the air. The result may not be in favour and may imply incomplete combustion. Finally, since density is directly related to viscosity, a density drop indicates a higher viscosity reading and a higher droplet size may be expected for discussion in the upcoming results. 


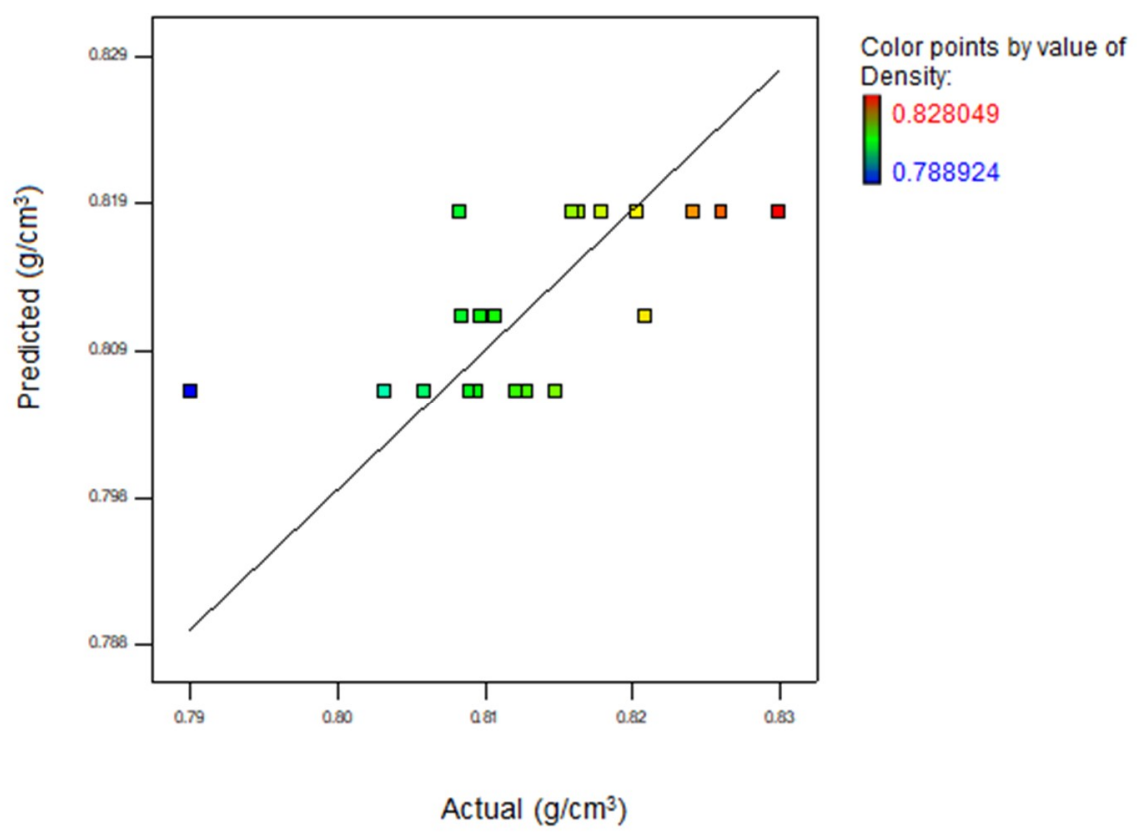

Figure 3. The experimental and predictive values of densities $\left(\mathrm{g} / \mathrm{cm}^{3}\right)$.

\subsection{Viscosity}

The final Equation in terms of coded factors is presented as in Equation (3). This is the equation that relates the listed input factors with interaction to the viscosity as the output response.

$$
\begin{gathered}
\mu=+3.01-0.16 A+0.039 B-0.027 D-0.024 A B-0.00813 A D+0.00688 B D \\
+0.028 A B D
\end{gathered}
$$

where $\mu$ is the dynamic viscosity.

The final equation in terms of actual factors is as in Equation (4):

$$
\begin{gathered}
\mu=+2.705+0.043 A+0.067 B+0.88125 D-0.00660 A B-0.12875 A D \\
-0.09875 B D+0.01125 A B D
\end{gathered}
$$

Viscosity readings of 20 samples were obtained and statistically analyzed. Figure 4a illustrates the computed effects for model selection via the half-normal probability plot in order to identify the biggest effect, which was the furthest point to the right. Interaction AD and BD were incorporated after manual regression in order to preserve the hierarchy. It is commonly known that the $t$-value scale provides a highly accurate measure of relative effects. Despite the factor interaction, AD and BD fall below the $\mathrm{t}$-value scale and $\mathrm{AD}$ and $\mathrm{BD}$ were not clicked off since they were involved in another significant interaction. In order to transform between coded and actual models, hierarchy must be supported. Otherwise, the coded model provides a different prediction in comparison to the actual model. Lack of a linear term by excluding nonsignificant factors and neglecting the hierarchy could lead to an incorrect conclusion. Hence, it was not a mistake or a botched factor argument consistent with Stat-Ease Consultation [50,51]. The diagnostic plot is presented as residuals versus run plot in Figure $4 \mathrm{~b}$, illustrating model quality. 


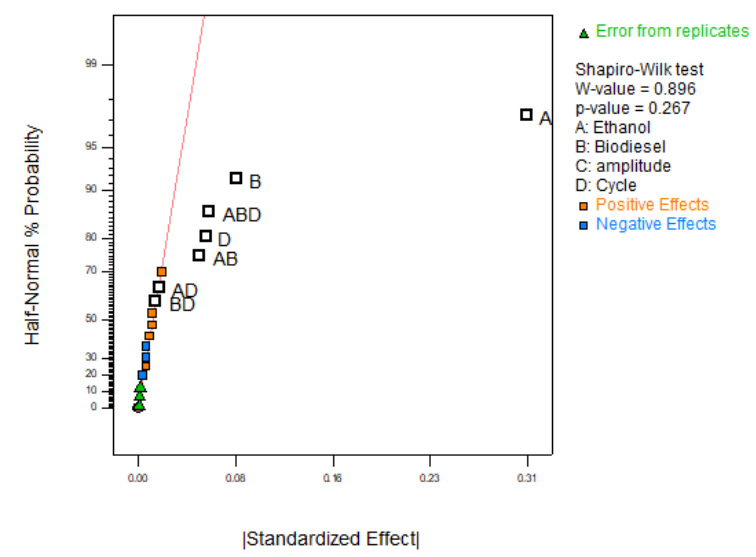

(a)

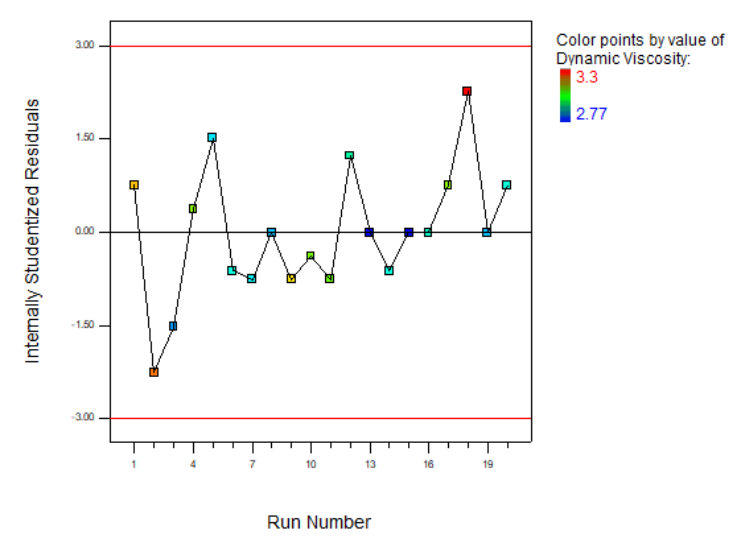

(b)

Figure 4. Viscosity reading (a) Viscosity half-normal plot; (b) residuals analysis plot.

As can be seen in Table 7, the probability value of the model indicates a statistically significant level. In this case, $\mathrm{A}, \mathrm{B}, \mathrm{D}, \mathrm{AB}$, and $\mathrm{ABD}$ are significant model terms, while $\mathrm{AD}$ and $\mathrm{BD}$ have $p$-values above 0.1000 , indicating they are not significant. The $p$-value for the curvature yield is significant, which indicates that the effect is not only in a linear form, but is more complex than that. For an additional $20 \%$ quality, to proceed to RSM is prudent [47]. Lack of fit testing shows a nonsignificant level which is desirable. Figure 5 demonstrates the predicted versus experimental plot with an acceptable random scattered point along the $45^{\circ}$ line.

Table 7. ANOVA for the selected factorial model (Partial sum of the square-Type III) for response 2 (Viscosity) with hierarchical terms added after manual regression (AD and BD).

\begin{tabular}{ccccccc}
\hline Source & $\begin{array}{c}\text { Sum of } \\
\text { Squares }\end{array}$ & df & $\begin{array}{c}\text { Mean } \\
\text { Square }\end{array}$ & $\begin{array}{c}\mathbf{F} \\
\text { Value }\end{array}$ & $\begin{array}{c}p \text {-Value } \\
\text { Prob }>\text { F }\end{array}$ & Remark \\
\hline Model & 0.450 & 7 & 0.064 & 182.79 & $<0.0001$ & significant \\
A-Ethanol & 0.390 & 1 & 0.390 & 1107.16 & $<0.0001$ & \\
B-Biodiesel & 0.025 & 1 & 0.025 & 70.87 & $<0.0001$ & \\
D-Cycle & 0.012 & 1 & 0.012 & 33.02 & 0.0001 & \\
AB & 0.009506 & 1 & 0.009506 & 27.16 & 0.0003 & \\
AD & 0.001056 & 1 & 0.001056 & 3.02 & 0.1102 & \\
BD & 0.0007563 & 1 & 0.0007563 & 2.16 & 0.1696 & \\
ABD & 0.013 & 1 & 0.013 & 36.16 & $<0.0001$ & significant \\
Curvature & 0.021 & 1 & 0.021 & 59.43 & $<0.0001$ & not significant \\
Residual & 0.003850 & 11 & 0.0003500 & & & \\
Lack of Fit & 0.003250 & 8 & 0.0004063 & 2.03 & 0.3026 & \\
Pure Error & 0.0006 & 3 & 0.000200 & & & \\
Cor Total & 0.470 & 19 & & & & \\
\hline
\end{tabular}

Figure 6a illustrates biodiesel-ethanol interaction with confidence bands subject to constant small cycle setting regardless of amplitude variation. Formulation of low ethanol with high biodiesel percentage yielded the highest viscosity reading. Meanwhile, with both low ethanol and biodiesel, the viscosity was lower. Furthermore, a formulation with high ethanol but low biodiesel exhibited a dramatic viscosity drop, but it was surprisingly slightly higher than samples with high biodiesel content. In another word, with both high ethanol and high biodiesel, the viscosity drop was higher. This indicates that ethanol is more dominant and has a direct influence on viscosity. When the cycle is lower, the proportionality of the interaction behavior slightly changes. Particularly, when the ethanol ratio is approximately above $12.50 \%$, the viscosity level is similar for both $5 \%$ and $15 \%$ biodiesel 
ratios. After the crossing point, the reduction level of the viscosity for low biodiesel content was lower compared to high biodiesel content.

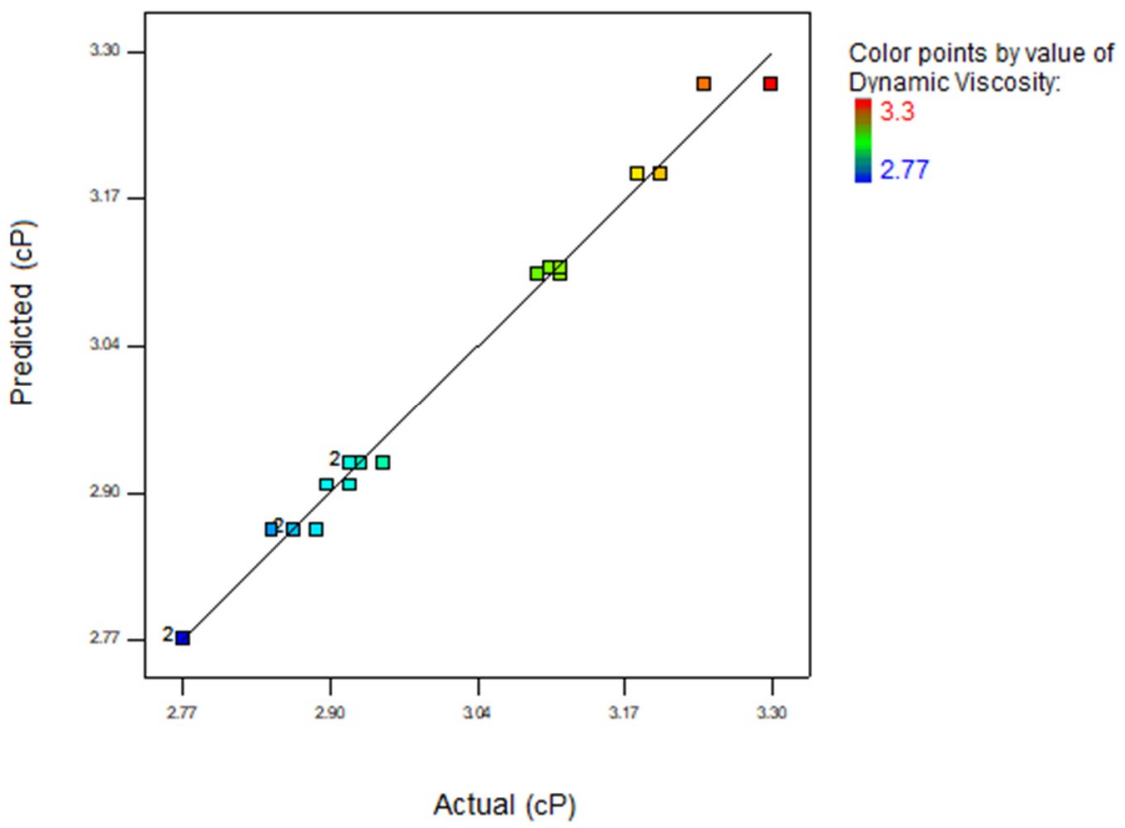

Figure 5. The experimental and predictive values of dynamic viscosity at $40{ }^{\circ} \mathrm{C}(\mathrm{cP})$.

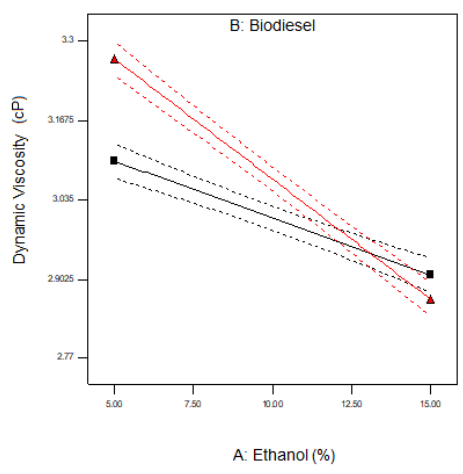

(a)

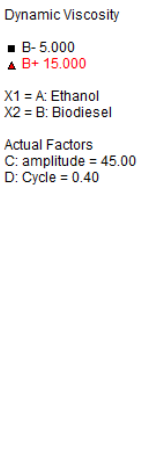

- $\begin{aligned} & \text { B- } 5.000 \\ & \text { B }+15.000\end{aligned}$

$\mathrm{X} 1=\mathrm{A}:$ : Ethanol
$\mathrm{X} 2=\mathrm{B}$ : Biodiesel

Actual Factors

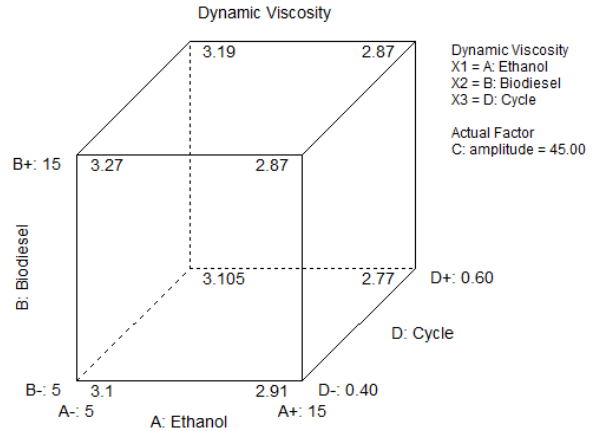

(b)

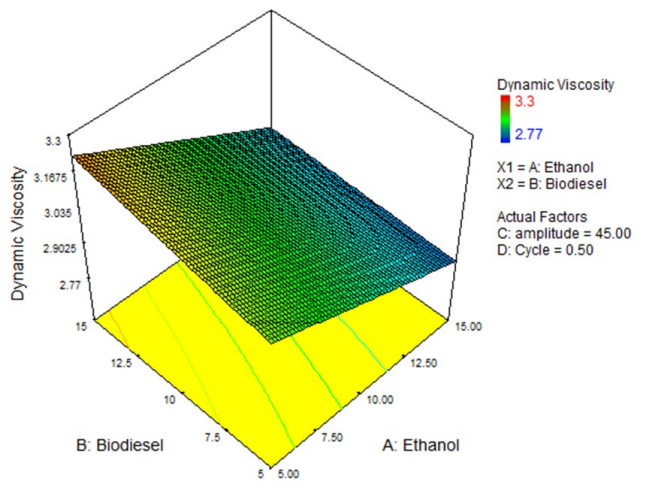

(c)

Figure 6. Biodiesel-ethanol interaction on viscosity (a) 2D presentation; (b) 3D surface presentation (c) Cube display. 
Low ethanol with a high percentage of biodiesel yielded the highest viscosity reading. However, when both ethanol and biodiesel are at low proportions, the viscosity value was found to be lower. Surprisingly, when both ethanol and biodiesel are high, a dramatic reduction in viscosity was observed. Again, ethanol's effect appears dominant over that of biodiesel. Furthermore, with high ethanol and a low setting of biodiesel, the viscosity drop was higher, as expected. With middle cycle range, regardless of high or low amplitude, the pattern was found to be almost the same as in Figure 6a, but without the cross point. In samples with high ethanol and high biodiesel, the viscosity drop was significant but slightly higher than in samples with low biodiesel content, as expected.

Figure $6 \mathrm{~b}, \mathrm{c}$ demonstrated ethanol, biodiesel, and cycle interactions when cycle and amplitude were at the middle of their range. Ethanol, biodiesel, and cycle settings were combined in order to affect the viscosity of the tri-fuel emulsion. The cube plot indicates that the lowest viscosity reading was when ethanol content and cycle setting were set at a high level and biodiesel ratio was set at a low level. The viscous condition occurs when biodiesel content is high, while the rest are set low. As stated earlier in the discussion of density results, viscosity plays an important role in the fuel atomization process.

\subsection{Surface Tension}

The final Equation regarding coded factors is presented as Equation (5). This is the equation that relates the listed input factors to the surface tension as the output response.

$$
\gamma=+25.40-1.26 \mathrm{~A}+0.25 B-0.081 C+0.43 D+0.36 A D-0.45 B C
$$

where $\gamma$ is the surface tension.

The final equation in terms of actual factors is Equation (6):

$$
\begin{gathered}
\gamma=+26.38750-0.60925 A+0.32150 B+0.05492 C-2.87500 D+0.71500 A D \\
-0.00603333 B C
\end{gathered}
$$

One of the important properties that could significantly affect the atomization process is the surface tension [52]. Surface tension readings of the 20 samples were obtained and statically analyzed. Figure 7a illustrates the computed effects for model selection via the half-normal probability plot in order to select the biggest effect, which is the point furthest to the right. Interaction $B$ and $C$ were incorporated after manual regression in order to preserve hierarchy. It is commonly known that the t-value scale provides a highly accurate measure of relative effects. Despite the factor interaction, B and $C$ fall below the $t$-value scale and were not clicked off since they were involved in another significant interaction. In order to transform between coded and actual models, hierarchy must be supported. Otherwise, the coded model provides a different prediction in comparison to the actual model. The lack of a linear term by excluding nonsignificant factors and neglecting the hierarchy could lead to an incorrect conclusion. Hence, it was not a mistake or a botched factor argument, consistent with Stat-Ease Consultation [50,51]. For counter checking, residuals analysis is needed. For this purpose, Figure $7 \mathrm{~b}$ presents the residuals analysis plot. In the residuals versus run plot, random scattering is observed and no pattern is detected, which indicates that the assumptions for ANOVA are met. 


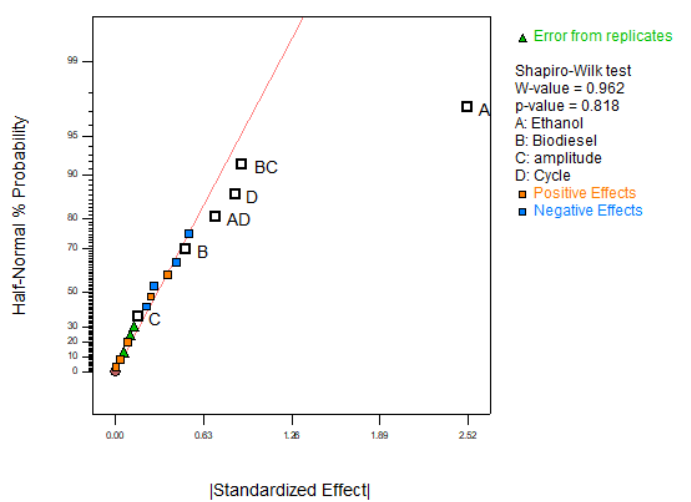

(a)

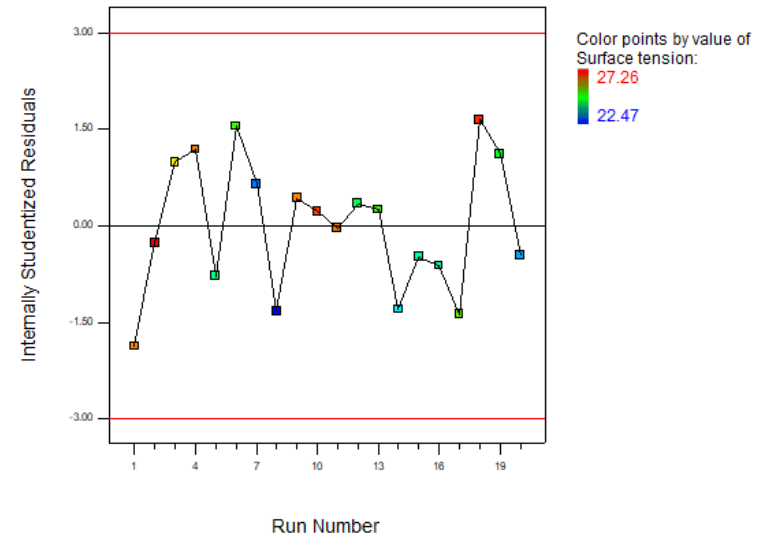

(b)

Figure 7. Surface tension half-normal plot (a) and residuals analysis plot (b).

As can be seen in Table 8, the probability value for the model is detected as significant. In this case, A, D, and AD. The curvature is detected as significant, which implies that the RSM is worth the effort [47]. Lack of fit testing shows a nonsignificant level, which is desirable. Figure 8 demonstrates the predicted versus experimental plot with an acceptable random scattered point along the $45^{\circ}$ line.

Table 8. ANOVA for the selected factorial model (Partial sum of the square-Type III) for response 3 (Surface tension) with hierarchical terms added after manual regression (B and C).

\begin{tabular}{ccccccc}
\hline Source & $\begin{array}{c}\text { Sum of } \\
\text { Squares }\end{array}$ & $\mathbf{d f}$ & $\begin{array}{c}\text { Mean } \\
\text { Square }\end{array}$ & $\begin{array}{c}\mathbf{F} \\
\text { Value }\end{array}$ & $\begin{array}{c}\boldsymbol{p} \text {-Value } \\
\text { Prob }>\mathbf{F}\end{array}$ & Remark \\
\hline Model & 34.70 & 6 & 5.78 & 15.31 & $<0.0001$ & significant \\
A-Ethanol & 25.35 & 1 & 25.35 & 67.10 & $<0.0001$ & \\
B-Biodiesel & 1.00 & 1 & 1.00 & 2.65 & 0.1297 & \\
C-amplitude & 0.11 & 1 & 0.11 & 0.28 & 0.6066 & \\
D-Cycle & 2.92 & 1 & 2.92 & 7.74 & 0.0166 & \\
AD & 2.04 & 1 & 2.04 & 5.41 & 0.0383 & \\
BC & 3.28 & 1 & 3.28 & 8.67 & 0.0123 & significant \\
Curvature & 3.79 & 1 & 3.79 & 10.04 & 0.0081 & \\
Residual & 4.53 & 12 & 0.38 & & & \\
Lack of Fit & 3.24 & 9 & 0.36 & 0.84 & 0.6335 & not significant \\
Pure Error & 1.29 & 3 & 0.43 & & & \\
Cor Total & 43.03 & 19 & & & & \\
\hline
\end{tabular}

High and low cycle settings interact with low ethanol content yield to similar surface tension results. A high cycle setting along with a low ethanol content yield high surface tension. For low cycle setting with low ethanol content, the surface tension is also high. High cycle setting with a high proportion of ethanol reduces the surface tension. However, low cycle with high ethanol content further reduced the surface tension. This indicates that cycle setting plays a significant role in maintaining the reading inclination from further reducing due to the influence of the ethanol. Figure 9 illustrates the interaction of amplitude and biodiesel on surface tension when cycle and ethanol content are at medium settings. Confidence bands are represented by the dotted lines. A low percentage of biodiesel with a high amplitude setting yields higher surface tension in comparison to low biodiesel content with low amplitude setting, although the difference is small. The surface tension oppositely responds to the high content of biodiesel regardless of amplitude setting. 


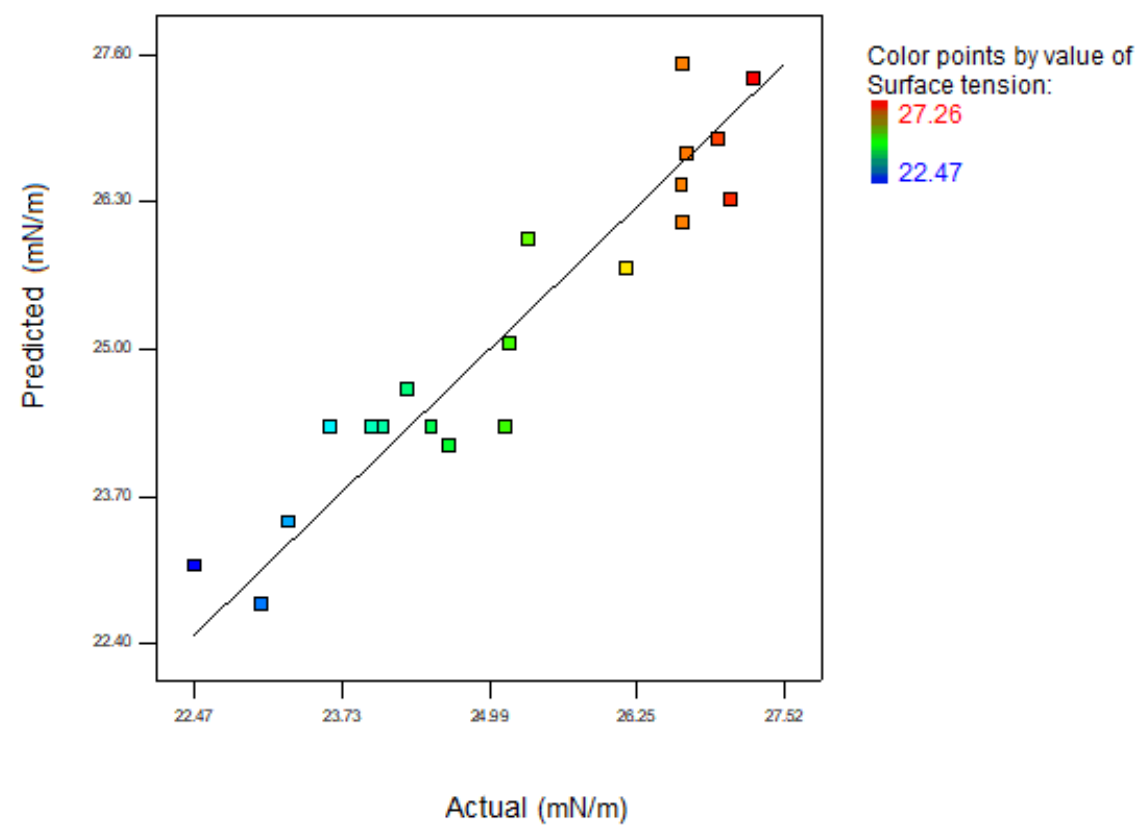

Figure 8. The experimental and predictive values of surface tension $(\mathrm{mN} / \mathrm{m})$.

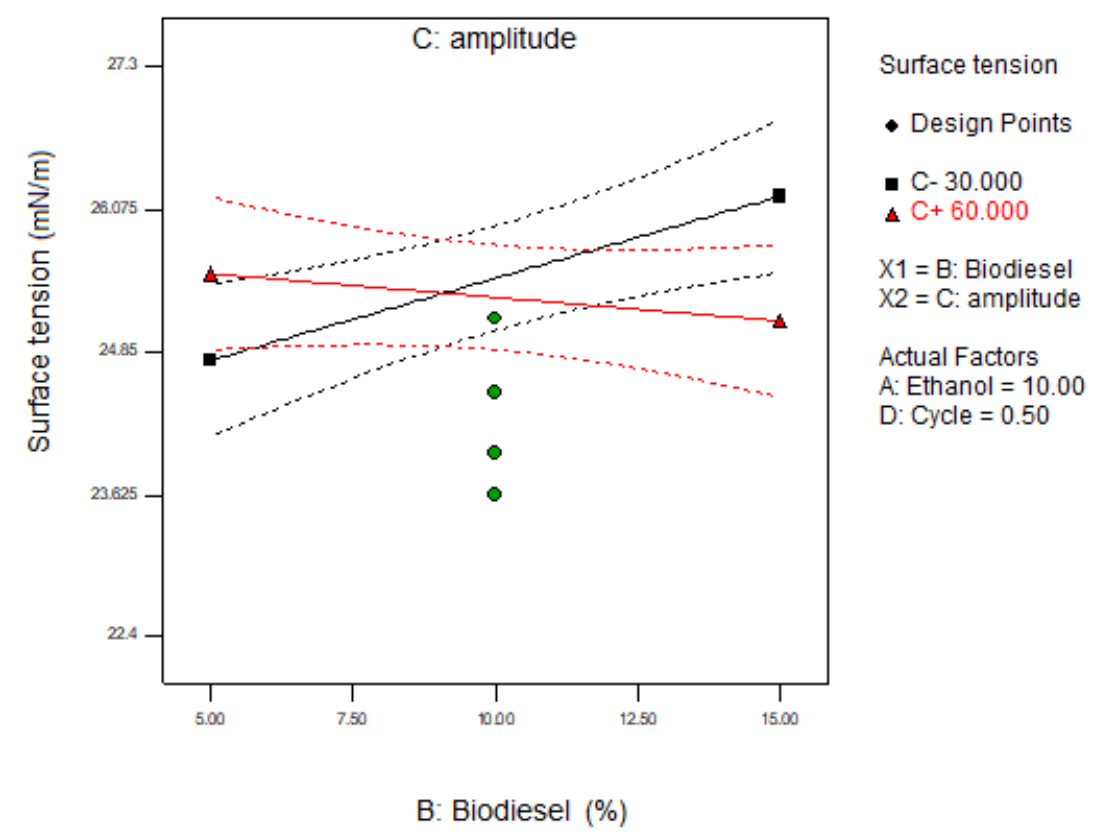

Figure 9. Two-factor interaction on surface tension.

\subsection{Average Droplet Size}

The final Equation in terms of coded factors is presented as in Equation (7). This is the equation that relates the listed input factors to the average droplet size.

$$
\begin{gathered}
\text { DAvg }=+1.05+0.16 B-0.41 C-0.47 D-0.26 B C-0.17 B D+0.48 C D \\
+0.30 B C D
\end{gathered}
$$

where DAvg is the average droplet size in microns. 
The final equation in terms of actual factors is Equation (8):

$$
\begin{gathered}
\mathrm{DAvg}=-0.763925+1.261885 B+0.047082 C+2.345125 D-0.023460 B C \\
-2.147875 B D-0.079717 C D+0.039988 B C D
\end{gathered}
$$

Average droplet size readings of 20 samples were obtained and statistically analyzed [50,51]. Most of the data were found to have high polydispersity index $(0.5>\mathrm{PdI}<1)$ and not under monodisperse $(>100 \mathrm{~nm})$ categories, fluorescence, and absorbance (coloured samples). Apparently, samples were almost too large for DLS measurement, particularly for determination of accurate average droplet size corresponding to mixing fuel under emulsion. Furthermore, possible errors may occur and result in a lack of precise particle size results, and hence may not be suitable for comparison with other methods of measurement [45]. In other words, other measurement techniques may yield dissimilar sizes for identical samples, meaning inter-method comparison is invalid. Besides, the limitation of the DLS technique was due to the existence of a non-spherical shape of the droplets. Evaluation of the average particle size measurement technique and its accuracy have been critically discussed [53,54]. Nevertheless, the results obtained did not defeat the experiment's objective, which was to recognize the interaction magnitude of four control factors on the characterized average droplet size range for all the prepared samples. To further clarify, it does not mean that the droplet sizes obtained by DLS are not useable considering the PdI values did not reach 1 or more, hence this is not an indicator to dismiss the technique. When comparing DLS data to conventional microscopy or counting-based techniques, the distribution is comparable. It is important, however, to emphasize that the objective of this study is not to compare between approaches, but to understand the effect of a few vital control factors on the behaviour of the droplet size produced.

Figure 10 demonstrates the computed effects for model selection via a half-normal probability plot (a) for the model selection. B and BD were incorporated after manual regression in order to preserve hierarchy. It is commonly known that the $\mathrm{t}$-value scale provides an accurate measure of relative effects. Despite factor interaction, B and BD fall below the t-value scale since they were involved in another significant interaction. In order to transform coded models into actual models, hierarchy must be supported. Otherwise, the coded model provides a different prediction than the actual model. Lack of a linear term by excluding nonsignificant factors and neglecting the hierarchy could lead to an incorrect conclusion. Hence, it was not a mistake or a botched factor argument, consistent with Stat-Ease Consultation $[50,51]$. Consequently, it depends on the other factors with which it interacts. Figure 10b displays the residual plot analysis for model assessment. The residuals versus run plot confirms that the assumptions for ANOVA are correct.

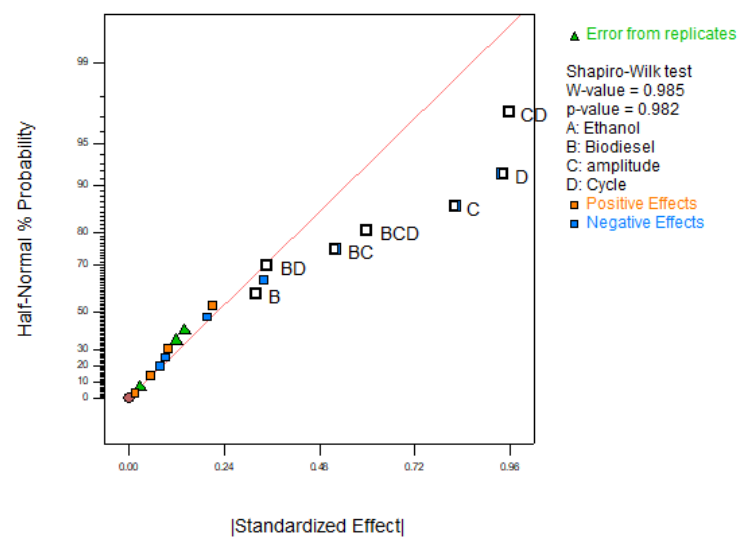

(a)

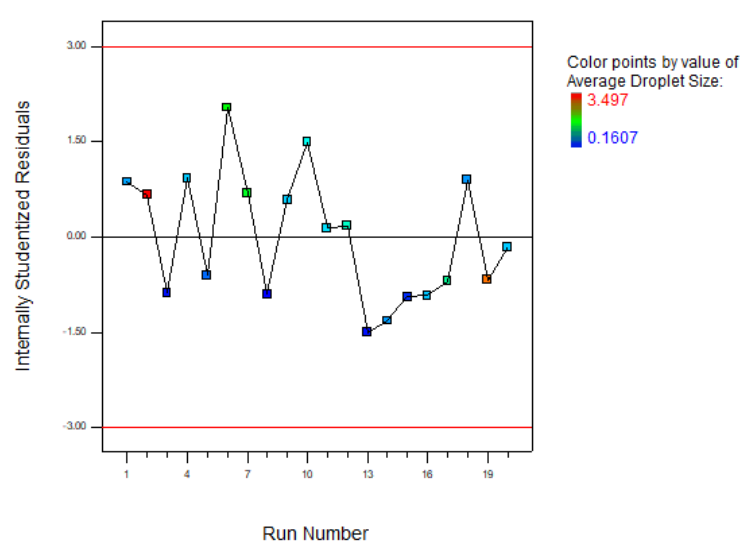

(b)

Figure 10. Average droplet size half-normal plot (a) and residuals analysis (b). 
As can be seen in Table 9, the probability value for the model is significant. In this case, C, D, BC, CD, and BCD are significant model terms, while values greater than 0.1000 indicate that the model terms are not significant. The curvature F value of 0.087 indicates that it is not necessary to proceed to RSM analysis [47]. The lack of fit test was nonsignificant, and this is desirable. Figure 11 illustrates the experimental and predictive values of average droplet size with an acceptable random scattered point along the $45^{\circ}$ line.

Table 9. ANOVA for the selected factorial model (Partial sum of the square-Type III) for response 4 (Average droplet size) with hierarchical terms added after manual regression (B and BD).

\begin{tabular}{ccccccc}
\hline Source & $\begin{array}{c}\text { Sum of } \\
\text { Squares }\end{array}$ & df & $\begin{array}{c}\text { Mean } \\
\text { Square }\end{array}$ & $\begin{array}{c}\text { F } \\
\text { Value }\end{array}$ & $\begin{array}{c}p \text {-Value } \\
\text { Prob }>\text { F }\end{array}$ & Remark \\
\hline Model & 13.39 & 7 & 1.91 & 12.45 & 0.0002 & Significant \\
B-Biodiesel & 0.41 & 1 & 0.41 & 2.67 & 0.1308 & \\
C-amplitude & 2.71 & 1 & 2.71 & 17.64 & 0.0015 & \\
D-Cycle & 3.57 & 1 & 3.57 & 23.27 & 0.0005 & \\
BC & 1.08 & 1 & 1.08 & 7.04 & 0.0225 & \\
BD & 0.49 & 1 & 0.49 & 3.16 & 0.1030 & \\
CD & 3.69 & 1 & 3.69 & 24.03 & 0.0005 & \\
BCD & 1.44 & 1 & 1.44 & 9.37 & 0.0108 & \\
Curvature & 0.013 & 1 & 0.013 & 0.087 & 0.7735 & not significant \\
Residual & 1.69 & 11 & 0.15 & & & \\
Lack of Fit & 0.91 & 8 & 0.11 & 0.44 & 0.8415 & not significant \\
Pure Error & 0.78 & 3 & 0.26 & & & \\
Cor Total & 15.09 & 19 & & & & \\
\hline
\end{tabular}

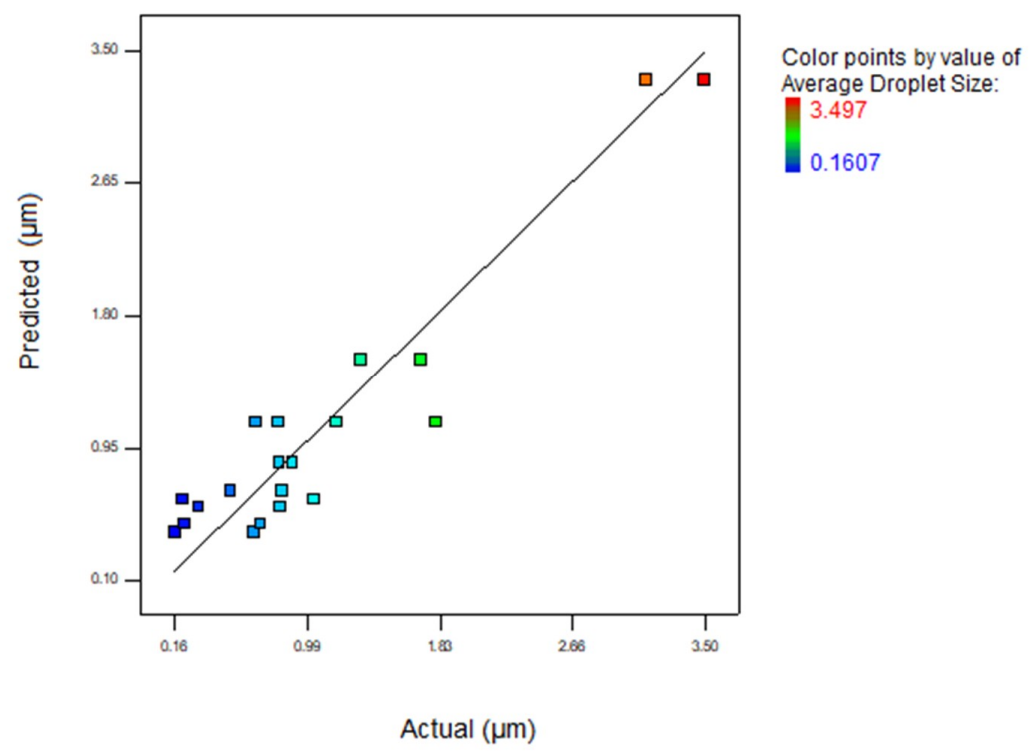

Figure 11. The experimental and predictive values of the average droplet size diameter in $\mu \mathrm{m}$.

Variation of ethanol percentage did not lead to any alteration in this case. Low or high amplitude with a small percentage of biodiesel resulted in no major difference to the average droplet size. However, with high biodiesel percentage, low amplitude contributed to a bigger size, while a high amplitude led to a more refined size. As expected, high cycle setting even with low amplitude lead to the formation of smaller droplet size, compared to low cycle setting accompanied by low amplitude. At high amplitude, regardless of high or low cycle setting, the average droplet size yielded an identical result. The obtained results presented no abnormal behavior, while the pattern slightly altered when biodiesel content was high in the mixture. Figure 12a above demonstrates the interaction between amplitude and cycle setting with respect to high biodiesel setting. The interaction can be observed 
when the amplitude is high, with both high and low cycle setting presenting opposite effects. The opposite effect, however, appeared to be minor. Increasing biodiesel content had nearly no effect with the increase of the amplitude level. However, a high percentage of biodiesel with low amplitude setting yielded a slightl larger average droplet size. Meanwhile, with high cycle setting, the interaction is similar to any combination of amplitude or biodiesel percentage. Figure $12 \mathrm{~b}$ illustrates the cube presentation of the interaction between biodiesel, amplitude, and cycle setting. Figure $12 \mathrm{c}$ displays a $3 \mathrm{D}$ representation of the interaction.

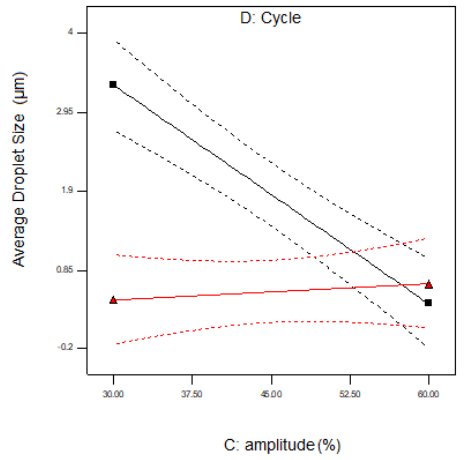

(a)

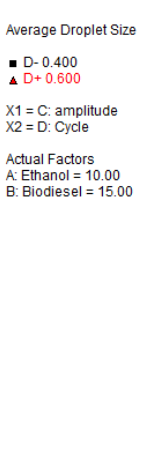

$1=C:$ amplitude
$2=D:$ Cycle
ctual Factors

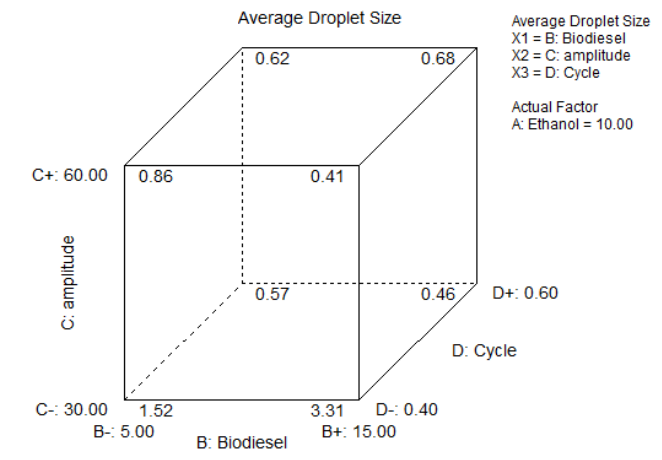

(b)

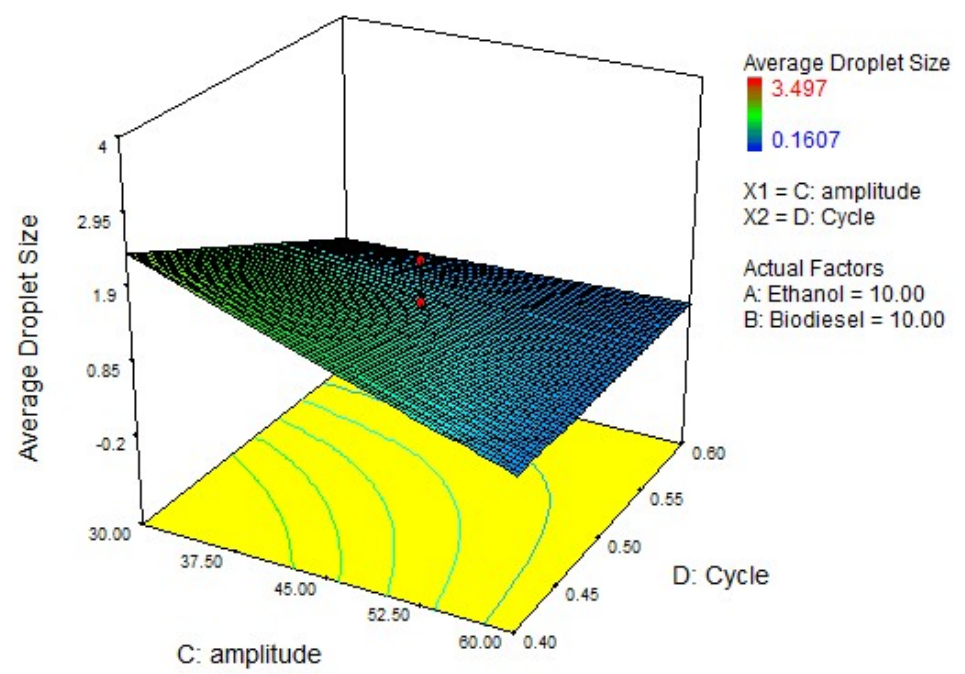

(c)

Figure 12. Interaction graphs for average droplet size. (a) 2D presentation; (b) 3D surface presentation (c) Cube display.

\subsection{Fuel Stability}

The experiment was to evaluate the duration in which the tri-fuel emulsions can survive with the experimental formulation ratio and emulsifying setting. It was observed that the samples prepared were not very stable and were subsequently subjected to phase separation after a couple of weeks, which is in agreement with a previous study [55]. In addition, rapid phase change was detected at initial stages. The shelf life of tri-fuel emulsion was predicted to be quite short and this was confirmed with experiments. A refresher is required to maintain the freshness and quality of the product. Through observation, two layers were visible which fluctuated over time due to evaporation and condensation.

Statistically, it was detected that ethanol has a significant influence on the density values in comparison to the rest of the control factors involved, as discussed in the density test result section. Nonetheless, the percentage contribution was $42.76 \%$, while the rest of the factors contributed less than $10 \%$ to the density reading. It was observed that while the separation phase took place, the ethanol 
layer separated as the top layer evaporated. Although each of the test tubes was under closed-cap conditions, the evaporated gas was trapped in the container and condensed when it lost its energy. This could be further explained by kinetic molecular theory. When molecules in the liquid are retained together with an attractive force, the molecules in the surface of the liquid absorb the heat energy from the atmosphere, hence the kinetic energy of the molecule in the liquid surface increases so that it can overcome the attractive forces and escape from the surface to the environment. This solely occurs when the energy of the absorption is sufficient to overcome the attractive force. Hence, it is not advisable to record the upper layer reading due to the fluctuation level. Thus, the bottom layer is the targeted region in order to obtain the optimum solution. This is comparable to a previous study [39].

Another phenomenon observed was moisture on the inner wall of the container. Eventually, the moisture became a droplet and was gravitationally pulled down and joined the original liquid. In instances where the humidity level outside the container was slightly high, the evaporated molecules that were trapped in the container were condensed and were attached to the wall of the container above the liquid level. The molecules lost energy due to the surrounding temperature. The molecules in the liquid absorbed the heat energy from the atmosphere in the container. In addition, it was observed that after the occurrence of phase separation, the upper layer of the liquid was alcohol, considering that the density value of alcohol is lower than the density of biodiesel or diesel.

Nonetheless, it was observed that in some cases the layer of alcohol settled down at the bottom of the test tube. This observation is doubtful but consistent with a number of repeated samples prepared with the same emulsifying setting and mixture ratio. The density of the alcohol mixed with diesel was found to not be constant, and this explains the bubble at the bottom of the container and is consistent with the previous experiment on other blended fuel categories involving diesel and alcohol mixtures [56].

Furthermore, on the first day upon preparation, phase separation activity was observed in the active stage. This could be due to the phase change from the nano-sized phase to the micron-sized phase due to coalition of dispersed droplets. Furthermore, the handling procedure during measurement and observation could have been a source of interruption. The phase separation was slower during weekly observations in comparison to the immediately prepared stage. Due to the interruption caused by minor motion during the measuring procedure, the separation rate tended to be disturbed and resulted in a slow process. However, during monthly observation, it was found that the separation speed rate accelerated in comparison to the weekly observation and this may be attributable to less interruption.

By using OFAT analysis, all samples from Table 5 were regrouped according to specific constant control factors as per Figure 13. The legend in Figure 13a-h represents fuel samples from Table 5. Figure 13a illustrates the samples with low cycle setting, while Figure 13b displays samples with high cycle setting. Figure 13c demonstrates samples with low amplitude setting, while Figure 13d shows samples with high amplitude setting. Figure 13e illustrates samples with low biodiesel content, while Figure $13 \mathrm{f}$ shows samples with high biodiesel content. Figure $13 \mathrm{~g}$ displays samples with low ethanol content, while Figure $13 \mathrm{~h}$ demonstrates samples with high ethanol content. According to the results obtained from the total 100 days of observation, three stages of behavior can be observed in all figures represented by the steepness of the slope. This is of significance since non-fresh tri-fuel emulsion, represented by the second and the third phases, may not possess similar physicochemical properties to other samples which were prepared at other times. Such behavior should not be overlooked and must be explored further. the steep slope observed in the first ten days indicates that the phase change behavior is highly active, followed by calmer conditions for the next 20-70 days. The aggressiveness of the coalition among dispersed droplets consists of trapped encapsulated volatile ethanol being reduced with time. This could be another key strategy in order to achieve microexplosion. It can be concluded from the stability observation that utilizing this fuel in CI engines may be challenging. Nevertheless, it is anticipated that the instability across the tested timeline could be a contributing factor to the vagueness of the occurrence of the microexplosions with tri-fuel emulsions in CI engines. This can be further investigated in the future. 


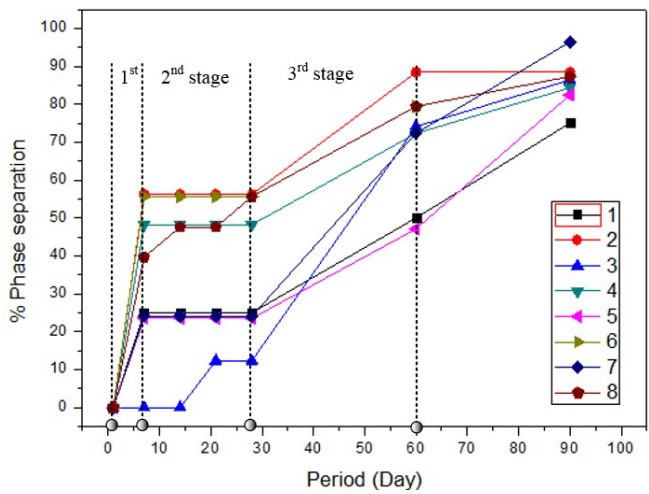

(a)

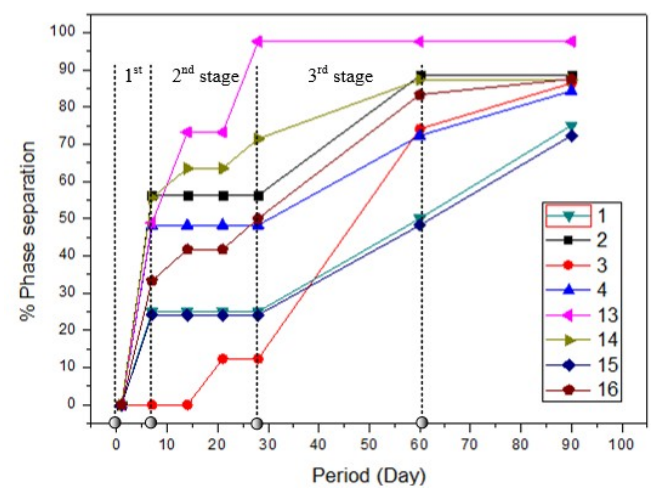

(c)

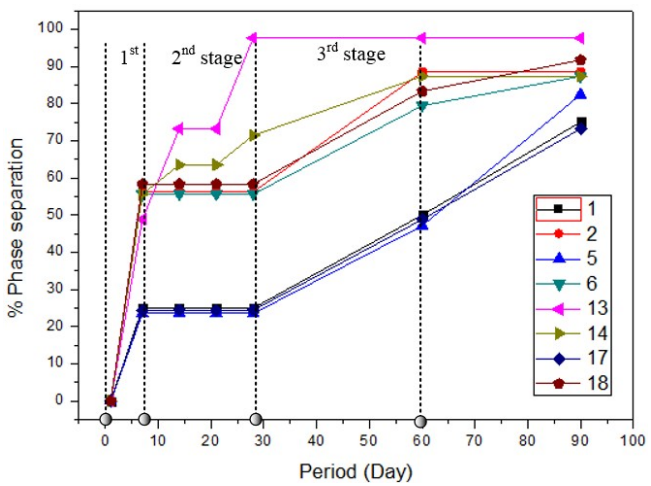

(e)

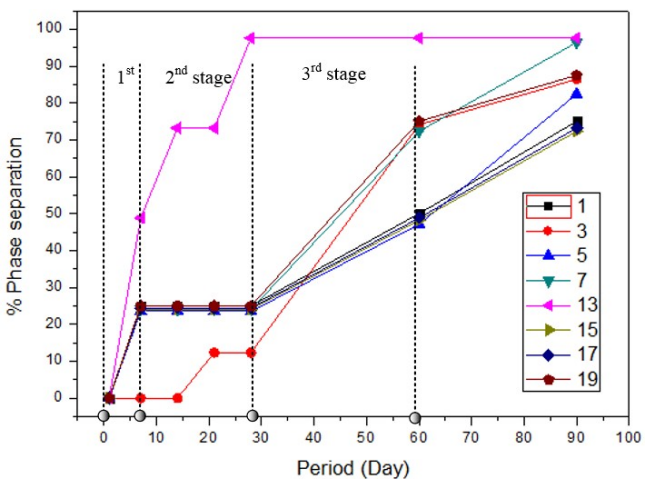

(g)

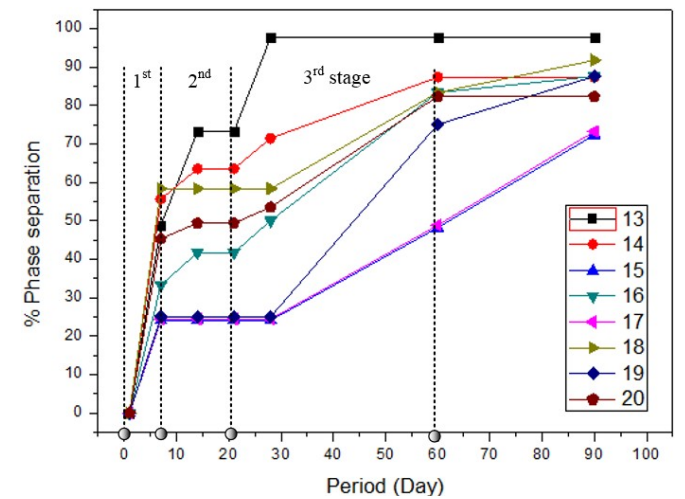

(b)

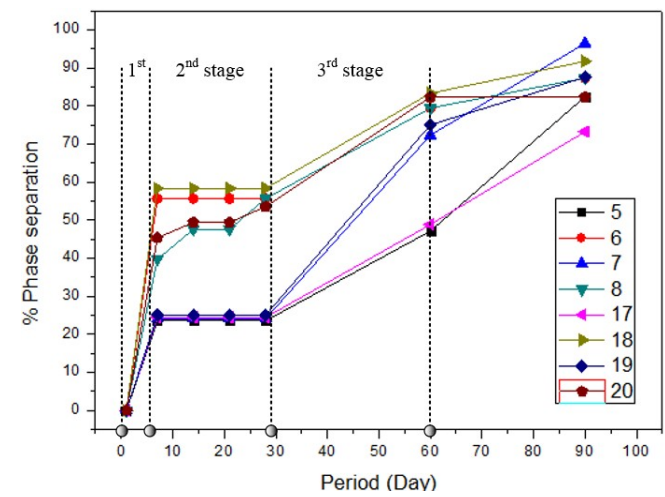

(d)

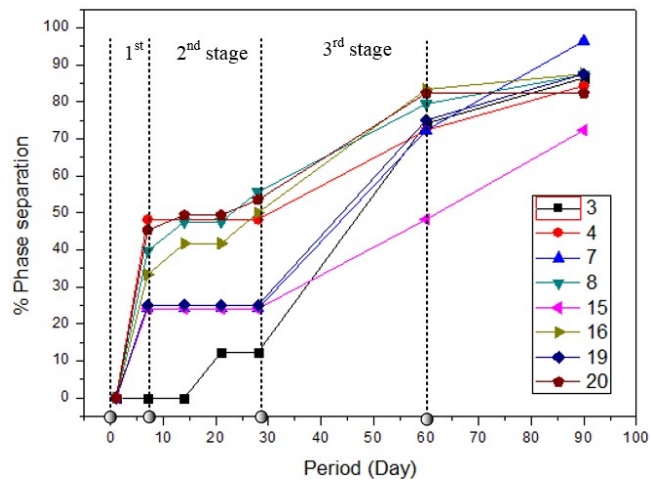

(f)

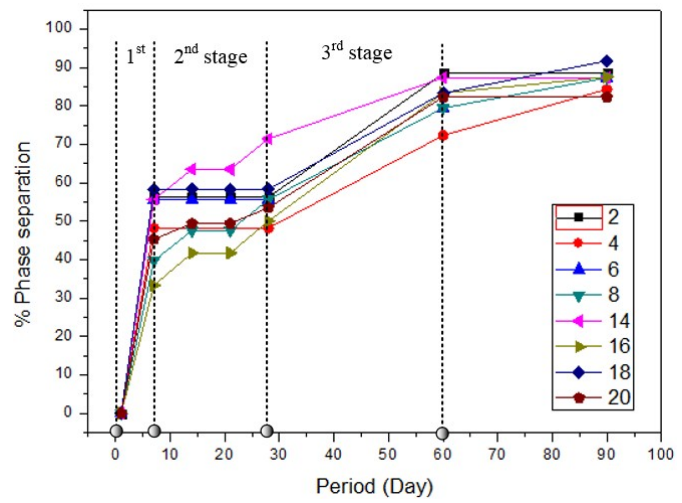

(h)

Figure 13. Stability behavior of tri-fuel emulsion subject to low cycle (a), high cycle (b), low amplitude (c), high amplitude (d), low biodiesel (e), high biodiesel (f), low ethanol (g), and high ethanol (h). 


\subsection{Microstructure}

Preinjected tri-fuel emulsion droplet microstructure was obtained. Twenty samples with the highest ethanol content (15\% alcohol by volume), highest biodiesel content (up to $15 \%$ by volume), $60 \%$ amplitude, and 0.6 s cycle were observed.

From the microphotograph, it can be observed that the dispersed ethanol is encapsulated within the surrounding biodiesel (Figure 14c). Such a phenomenon would not be observed solely in diesel, biodiesel, or ethanol. The average diameter size of the capsule was estimated to be approximately $1 \mu \mathrm{m}$ to $10 \mu \mathrm{m}$. The state of the droplet in constant motion may be due to the surrounding conditions and procedure interruption. Collisions among dispersed droplets were observed, which is consistent with previous studies $[36,38,55]$. Although Figure $14 a, b$ showed completely round droplet shape, the shape of the encapsulated droplets were not perfectly round, and Figure $14 \mathrm{c}$, $\mathrm{d}$ shows a more oval shape. This geometry may or may not favour microexplosion, as suggested in the emulsified oil and water study [57]. Due to aerodynamic effect, the location of the dispersed component in the droplet may change, resulting in oval-shaped droplets. Hence, additional energy is required on certain sides of the dispersed droplet geometry in order to enable the micro-explosion phenomenon to transpire.

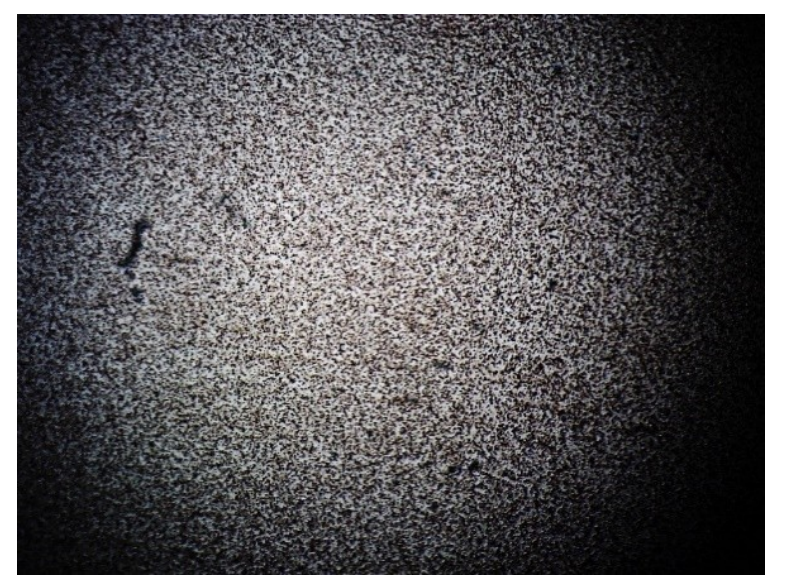

(a)

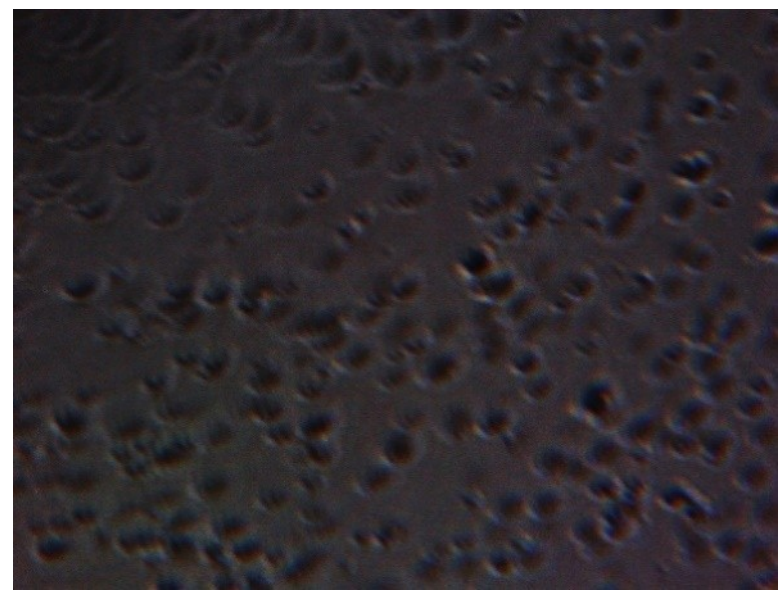

(c)

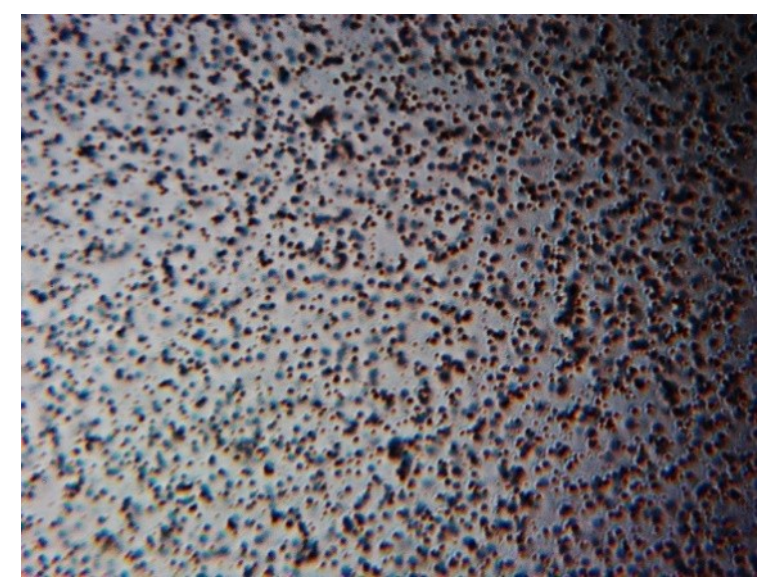

(b)

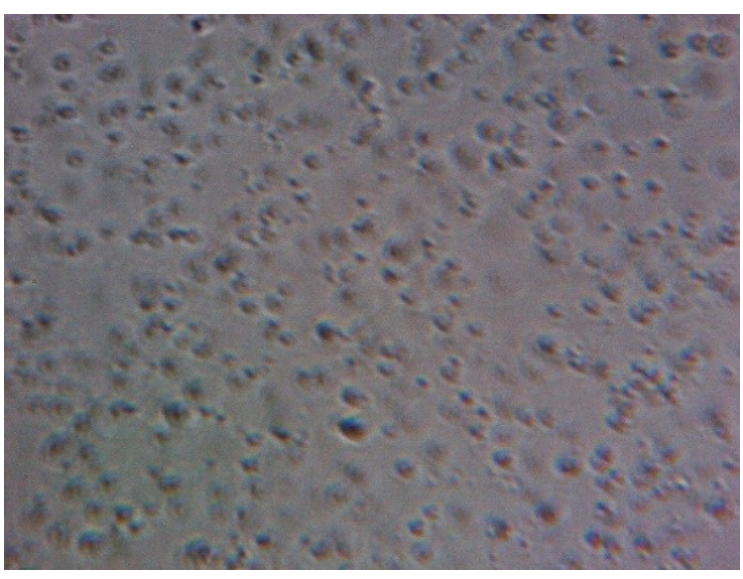

(d)

Figure 14. Microphotographs of tri-fuel emulsion with a $5 \times$ objective lens and a bright backlight (a), $10 \times$ objective lens and bright backlight (b), 40× objective lens and dim backlight (c), and 40× objective lens with bright backlight $(\mathbf{d})$. 


\section{Conclusions}

Tri-fuel emulsions were prepared with the emulsifying setting and formulation ratio as control factors. Experiments were performed in order to evaluate the effect of emulsifying setting and formulation ratio on selective physicochemical properties of tri-fuel emulsions. A commercial DOE software with built-in features, such as effect detection, ANOVA, diagnostics, and model graphs, was employed for detection of responses such as density, viscosity, surface tension, and average droplet size.

A gravitational approach for stability analysis was conducted using OFAT analysis. Qualitative experiments of tri-fuel emulsion microstructure revealed that dispersed droplets were not of a perfectly round shape. This finding is important for analysis of the microexplosion phenomenon in the future, considering that the non-spherical shape could affect the process of secondary atomization. According to the density results, while incorporation of biodiesel increased the density of tri-fuel emulsion, this was offset by a major influence of ethanol, which indicates that tri-fuel emulsions' density can be optimized by varying the ethanol content. Furthermore, the dynamic viscosity response was consistent with the literature. In addition, minor variation in results may be expected when a high content of ethanol is utilized.

Meanwhile, the surface tension response showed that the amplitude setting interaction with biodiesel is almost the opposite of the interaction of cycle with ethanol content. For viscosity and surface tension response, however, subsequent experimentation is required considering both were analyzed with curvature detection. The curvature detected for viscosity and surface tension in this study is an excellent indicator for further exploration of the RSM approach for optimization work.

The effect of amplitude and cycle setting on the average droplet size response was obvious with longer and higher triggered ultrasonic output, which resulted in a more refined average droplet size. In addition, the stability test indicated that the nano- to micro-phase transformation resulted in unstable tri-fuel emulsions. Nevertheless, understanding the pattern of stability could assist in microexplosion experiments.

Optimization based on control factors utilized in this study can be employed to proceed with engine performance and emission studies, with the specific goal of the investigation of the microexplosion phenomenon of tri-fuel emulsions in CI engines.

Author Contributions: Conceptualization, M.M.N.A. and F.Y.H.; Methodology, M.M.N.A. and F.Y.H; Software, M.M.N.A. and K.K..; Validation, F.Y.H, R.M. and A.R.A.A.; Formal Analysis, M.M.N.A. and F.Y.H; Investigation, M.M.N.A.; Resources, M.M.N.A. and F.Y.H; Data Curation, M.M.N.A. and F.Y.H; Writing-Original Draft Preparation, M.M.N.A. and F.Y.H; Writing-Review \& Editing, F.Y.H, A.A.A. and M.M.N.; Visualization, M.M.N.A. and K.K.; Supervision, F.Y.H, R.M. and A.R.A.A; Project Administration, F.Y.H; Funding Acquisition, A.R.A.A.

Funding: The funding information from Ministry of Education, Malaysia is acknowledged.

Acknowledgments: This work was conducted under the financial support of Universiti Malaysia Pahang with the internal grant PGRS180344 and Ministry of Education, Malaysia grant through RDU150124 (FRGS/1/2015/TK07/UMP/02/2) and RDU160152.

Conflicts of Interest: The authors declare no conflicts of interest.

\section{References}

1. The Freedonia Group Inc. Global Diesel Engine Sales Forecast to Rise 7.7 Percent a Year; Biodiesel Mag 4/29/2014; The Freedonia Group Inc.: Cleveland, OH, USA, 2014.

2. Hegab, A.; La, A.; Shayler, P. Towards keeping diesel fuel supply and demand in balance: Dual-fuelling of diesel engines with natural gas. Renew. Sustain. Energy Rev. 2016, 70. [CrossRef]

3. Meikap, B.C.; Swar, A.K.; Mohanty, C.; Sahu, J.N.; Hung, Y. Air polution and its control. In Handbook of Environment and Waste Management; World Scientific: Singapore, 2012; pp. 1-39, ISBN 9789814327701. [CrossRef]

4. Nemmar, A.; Hoet, P.H.M.; Dinsdale, D.; Vermylen, J.; Hoylaerts, M.F.; Nemery, B. Diesel exhaust particles in lung acutely enhance experimental peripheral thrombosis. Circulation 2003, 107, 1202-1208. [CrossRef] [PubMed] 
5. Hussain, J.; Palaniradja, K.; Alagumurthi, N.; Manimaran, R. Effect of Exhaust Gas Recirculation (EGR) on performance and emission characteristics of a three cylinder direct injection compression ignition engine. Alexandria Eng. J. 2012, 51, 241-247. [CrossRef]

6. Mofijur, M.; Rasul, M.G.; Hyde, J.; Azad, A.K.; Mamat, R.; Bhuiya, M.M.K. Role of biofuel and their binary (diesel-biodiesel) and ternary (ethanol-biodiesel-diesel) blends on internal combustion engines emission reduction. Renew. Sustain. Energy Rev. 2016, 53, 265-278. [CrossRef]

7. Harris, S.J.; Maricq, M.M. Signature size distributions for diesel and gasoline engine exhaus particulate matter. J. Aerosol Sci. 2001, 32, 749-764. [CrossRef]

8. Rasul, M.G.; Taweekun, J.; Ashrafur, S.M.; Mofijur, M.; Mahlia, T.M.I.; Techato, K.; Uddin, M.N. An Overview of Recent Developments in Biomass Pyrolysis Technologies. Energies 2018, 11, 3115. [CrossRef]

9. Aditiya, H.B.; Mahlia, T.M.I.; Chong, W.T.; Nur, H.; Sebayang, A.H. Second generation bioethanol production: A critical review. Renew. Sustain. Energy Rev. 2016, 66, 631-653. [CrossRef]

10. Anwar, M.; Rasul, M.G.; Ashwath, N.; Rahman, M.M. Optimisation of Second-Generation Biodiesel Production from Australian Native Stone Fruit Oil Using Response Surface Method. Energies 2018, 11, 2566. [CrossRef]

11. Rahman, M.M.; Rasul, M.; Hassan, N.M.S. Study on the tribological characteristics of Australian native first generation and second generation biodiesel fuel. Energies 2017, 10, 55. [CrossRef]

12. Mahmudul, H.M.; Hagos, F.Y.; Mamat, R.; Adam, A.A.; Ishak, W.F.W.; Alenezi, R. Production, characterization and performance of biodiesel as an alternative fuel in diesel engines-A review. Renew. Sustain. Energy Rev. 2017, 72, 497-509. [CrossRef]

13. Rahman, M.M.; Rasul, M.; Hassan, N.M.S.; Hyde, J. Prospects of biodiesel production from macadamia oil as an alternative fuel for diesel engines. Energies 2016, 9, 403. [CrossRef]

14. Venu, H.; Madhavan, V. Influence of diethyl ether (DEE) addition in ethanol-biodiesel-diesel (EBD) and methanol-biodiesel-diesel (MBD) blends in a diesel engine. Fuel 2017, 189, 377-390. [CrossRef]

15. Park, S.H.; Kim, S.H.; Lee, C.S. Mixing stability and spray behavior characteristics of diesel-ethanol-methyl ester blended fuels in a common-rail diesel injection system. Energy Fuels 2009, 23, 5228-5235. [CrossRef]

16. Corral-Gómez, L.; Rubio-Gómez, G.; Martínez-Martínez, S.; Sánchez-Cruz, F.A. Effect of diesel-biodiesel-ethanol blends on the spray macroscopic parameters in a common-rail diesel injection system. Fuel 2019, 241, 876-883. [CrossRef]

17. Botero, M.L.; Huang, Y.; Zhu, D.L.; Molina, A.; Law, C.K. Synergistic combustion of droplets of ethanol, diesel and biodiesel mixtures. Fuel 2012, 94, 342-347. [CrossRef]

18. Liu, Y.; Cheng, W.L.; Huo, M.; Lee, C.F.; Li, J.; City, C.C.; Province, J.L.; Street, W.G. Effects of Micro-Explosion on Butanol-Biodiesel-Diesel Spray and Combustion. In Proceedings of the ILASS-Americas 22nd Annual Conference on Liquid Atomization and Spray Systems, Cincinnati, OH, USA, 16-19 May 2010.

19. Liu, Y.; Li, J.; Jin, C. Fuel spray and combustion characteristics of butanol blends in a constant volume combustion chamber. Energy Convers. Manag. 2015, 105, 1059-1069. [CrossRef]

20. Avulapati, M.M.; Ganippa, L.C.; Xia, J.; Megaritis, A. Puffing and micro-explosion of diesel-biodiesel-ethanol blends. Fuel 2016, 166, 59-66. [CrossRef]

21. Han, K.; Yang, B.; Zhao, C.; Fu, G.; Ma, X.; Song, G. Experimental study on evaporation characteristics of ethanol-diesel blend fuel droplet. Exp. Therm. Fluid Sci. 2016, 70, 381-388. [CrossRef]

22. Alptekin, E. Emission, injection and combustion characteristics of biodiesel and oxygenated fuel blends in a common rail diesel engine. Energy 2017, 119, 44-52. [CrossRef]

23. Zhan, C.; Feng, Z.; Ma, W.; Zhang, M.; Tang, C.; Huang, Z. Experimental investigation on effect of ethanol and di-ethyl ether addition on the spray characteristics of diesel/biodiesel blends under high injection pressure. Fuel 2018, 218, 1-11. [CrossRef]

24. Avulapati, M.M.; Megaritis, T.; Xia, J.; Ganippa, L. Experimental understanding on the dynamics of micro-explosion and puffing in ternary emulsion droplets. Fuel 2019, 239, 1284-1292. [CrossRef]

25. Boggavarapu, P.; Ravikrishna, R.V. Evaporating spray characteristics of a diesel-ethanol micro-emulsion. Fuel 2019, 246, 104-107. [CrossRef]

26. Fernando, S.; Hanna, M. Development of a novel biofuel blend using ethanol-biodiesel-diesel microemulsions: EB-diesel. Energy Fuels 2004, 18, 1695-1703. [CrossRef] 
27. Hulwan, D.B.; Joshi, S.V. Performance, emission and combustion characteristic of a multicylinder DI diesel engine running on diesel-ethanol-biodiesel blends of high ethanol content. Appl. Energy 2011, 88, 5042-5055. [CrossRef]

28. Lapuerta, M.; Armas, O.; García-Contreras, R. Effect of ethanol on blending stability and diesel engine emissions. Energy Fuels 2009, 23, 4343-4354. [CrossRef]

29. Khoobbakht, G.; Najafi, G.; Karimi, M.; Akram, A. Optimization of operating factors and blended levels of diesel, biodiesel and ethanol fuels to minimize exhaust emissions of diesel engine using response surface methodology. Appl. Therm. Eng. 2016, 99, 1006-1017. [CrossRef]

30. Mahmudul, H.M.; Hagos, F.Y.; Mukhtar, M.N.A.; Mamat, R.; Adam Abdullah, A. Effect of Alcohol on Diesel Engine Combustion Operating with Biodiesel-Diesel Blend at Idling Conditions. IOP Conf. Ser. Mater. Sci. Eng. 2018, 318. [CrossRef]

31. Seifi, M.R.; Hassan-Beygi, S.R.; Ghobadian, B.; Desideri, U.; Antonelli, M. Experimental investigation of a diesel engine power, torque and noise emission using water-diesel emulsions. Fuel 2016, 166, 392-399. [CrossRef]

32. Guo, Z.G.; Wang, S.R.; Wang, X.Y. Emulsification of Bio-Oil Heavy Fraction with Diesel by Mechanical and Ultrasonic Technologies. Appl. Mech. Mater. 2013, 316-317, 1133-1137. [CrossRef]

33. Lin, C.Y.; Chen, L.W. Emulsification characteristics of three- and two-phase emulsions prepared by the ultrasonic emulsification method. Fuel Process. Technol. 2006, 87, 309-317. [CrossRef]

34. Hielscher, T. Ultrasonic Production of Nano-Size Dispersions and Emulsions. arxiv 2007, arXiv:0708.1831.

35. Guo, Z.G.; Yin, Q.Q.; Wang, S.R. Bio-Oil Emulsion Fuels Production Using Power Ultrasound. Adv. Mater. Res. 2011, 347-353, 2709-2712. [CrossRef]

36. Mehta, R.N.; Chakraborty, M.; Parikh, P.A. Comparative study of stability and properties of alcohol-diesel blends. Int. J. Chem. Technol. 2012, 19, 134-139.

37. Bahrudin, M.N.H.M.; Mukhtar, A.N.; Hagos, F.Y.; Mamat, R.; Abdullah, A.A.; Karim, Z.A.A. Comparison between tri-fuel (diesel-ethanol-biodiesel) emulsion with and without surfactant. AIP Conf. Proc. 2019, 2059. [CrossRef]

38. Lee, K.H.; Mukhtar, M.N.A.; Hagos, F.Y.; Noor, M.M. A study of the stabilities, microstructures and fuel characteristics of tri-fuel (diesel-biodiesel-ethanol) using various fuel preparation methods. IOP Conf. Ser. Mater. Sci. Eng. 2017, 257. [CrossRef]

39. Low, M.H.; Mukhtar, M.N.A.; Hagos, F.Y.; Noor, M.M. Tri-fuel (diesel-biodiesel-ethanol) emulsion characterization, stability and the corrosion effect. IOP Conf. Ser. Mater. Sci. Eng. 2017, 257. [CrossRef]

40. Brarad, M. Strategies and Techniques for Quality and Flexibility; Warsaw, P., Ed.; Tel Aviv: Briefs in Applied Sciences and Technology; Springer: Berlin/Heidelberg, Germany, 2018; ISBN 9783319683997. [CrossRef]

41. Yusri, I.M.; Mamat, R.; Azmi, W.H.; Omar, A.I.; Obed, M.A.; Shaiful, A.I.M. Application of response surface methodology in optimization of performance and exhaust emissions of secondary butyl alcohol-gasoline blends in SI engine. Energy Convers. Manag. 2017, 133, 178-195. [CrossRef]

42. Suhaimi, H.; Adam, A.; Mrwan, A.G.; Abdullah, Z.; Othman, M.F.; Kamaruzzaman, M.K.; Hagos, F.Y. Analysis of combustion characteristics, engine performances and emissions of long-chain alcohol-diesel fuel blends. Fuel 2018, 220, 682-691. [CrossRef]

43. Wang, X.Y.; Guo, Z.G.; Wang, S.R. Emulsion Fuels Production between Diesel and Bio-Oil Middle Fraction from Molecular Distillation. Adv. Mater. Res. 2012, 534, 151-155. [CrossRef]

44. Sales, R.S.; Support, A. Dynamic Light Scattering Training Achieving Reliable Nano Particle Sizing. 2014. Available online: http://149.171.168.221/partcat/wp- (accessed on 13 March 2019).

45. Fischer, K.; Schmidt, M. Pitfalls and novel applications of particle sizing by dynamic light scattering. Biomaterials 2016, 98, 79-91. [CrossRef]

46. Reham, S.S.; Masjuki, H.H.; Kalam, M.A.; Shancita, I.; Rizwanul Fattah, I.M.; Ruhul, A.M. Study on stability, fuel properties, engine combustion, performance and emission characteristics of biofuel emulsion. Renew. Sustain. Energy Rev. 2015, 52, 1566-1579. [CrossRef]

47. Anderson, M.J.; Whitcomb, P.J. RSM Simplified: Optimizing Processes Using Response Surface Methods for Design of Experiments; Productivity Press: New York, NY, USA, 2016; ISBN 9781498745987.

48. Ali, O.M.; Mamat, R.; Abdullah, N.R.; Abdullah, A.A. Analysis of blended fuel properties and engine performance with palm biodiesel-diesel blended fuel. Renew. Energy 2015, 86, 59-67. [CrossRef] 
49. Park, S.H.; Suh, H.K.; Lee, C.S. Nozzle flow and atomization characteristics of ethanol blended biodiesel fuel. Renew. Energy 2010, 35, 144-150. [CrossRef]

50. Anderson, M.J.; Whitcomb, P.J.; Kraber, S.L.; Adams, W. Stat-Ease Handbook for Experimenters, version 10; Stat-Ease Inc.: Minneapolis, MN, USA, 2016.

51. Anderson, M.J.; Whitcomb, P.J.; Kraber, S.L.; Adams, W. at-Ease Handbook for Experimenters, version 11; Stat-Ease Inc.: Minneapolis, MN, USA, 2018.

52. Ejim, C.E.; Rahman, M.A.; Amirfazli, A.; Fleck, B.A. Effects of liquid viscosity and surface tension on atomization in two-phase, gas/liquid fluid coker nozzles. Fuel 2010, 89, 1872-1882. [CrossRef]

53. Bhattacharjee, S. DLS and zeta potential - What they are and what they are not? J. Control. Release 2016, 235, 337-351. [CrossRef]

54. Bhattacharjee, S. In relation to the following article "DLS and zeta potential-What they are and what they are not?" Journal of Controlled Release, 2016, 235, 337-351. J. Control. Release 2016, 238, 311-312. [CrossRef]

55. Tan, Y.H.; Abdullah, M.O.; Nolasco-Hipolito, C.; Zauzi, N.S.A.; Abdullah, G.W. Engine performance and emissions characteristics of a diesel engine fueled with diesel-biodiesel-bioethanol emulsions. Energy Convers. Manag. 2017, 132, 54-64. [CrossRef]

56. Kato, M.; Muramatsu, T.; Tanaka, H.; Moriya, S.; Yaginuma, F.; Isshiki, N. Density Behavior of Alcohol-Diesel Fuel Mixtures. J. Jpn. Pet. Inst. 1991, 34, 186-190. [CrossRef]

57. Fu, W.B.; Hou, L.Y.; Wang, L.; Ma, F.H. A unified model for the micro-explosion of emulsified droplets of oil and water. Fuel Process. Technol. 2002, 79, 107-119. [CrossRef]

(C) 2019 by the authors. Licensee MDPI, Basel, Switzerland. This article is an open access article distributed under the terms and conditions of the Creative Commons Attribution (CC BY) license (http://creativecommons.org/licenses/by/4.0/). 